\title{
ÖRGÜTSEL BAĞLAMDA DUYGUSAL ZEKA VE IŞ TATMINi
}

Necmettin GÜL 


\section{(C) Copyright 2020}

Bu kitabın, basım, yayın ve satış hakları Akademisyen Kitabevi A.Ş.'ne aittir. Anılan kuruluşun izni alınmadan kitabın tümü ya da Bölümleri mekanik, elektronik, fotokopi, manyetik kağıt ve/veya başka yöntemlerle çoğaltılamaz, basılamaz, dağtılamaz. Tablo, şekil ve grafikler izin alınmadan, ticari amaçh kullanılamaz. Bu

kitap T.C. Kültür Bakanlı̆̆ bandrolü ile satılmaktadır.

ISBN

978-625-7707-65-7

\section{Kitap Adı}

Örgütsel Bağlamda Duygusal Zeka ve İş Tatmini

Yazar

Necmettin GÜL

ORCID iD: 0000-0001-9497-5674

\section{Yayın Koordinatörü}

Yasin Dilmen

Sayfa ve Kapak Tasarımı

Akademisyen Dizgi Ünitesi

Yayıncı Sertifika No

47518

Baskı ve Cilt

Vadi Matbaacilık

Bisac Code

BUS085000

DOI

10.37609/akya.828

\section{GENEL DAĞITIM}

\section{Akademisyen Kitabevi A.Ş.}

Halk Sokak 5 / A

Yenişehir / Ankara

Tel: o312 4311633

siparis@akademisyen.com 


\section{IÇINDEKILER}

Ön Söz iii

Kısaltmalar Listesi iv

1. GiRiş .1

2. KONU İLE ILGILI ÖNCEKI ARAŞTIRMALAR ...................................5

3. DUYGUSAL ZEKA KAVRAMI VE KAPSAMI ..............................21

3.1. Duygu ve Zeka Kavramlarının Tanımı ....................................................21

3.1.1. Duygu Kavramı ...............................................................................21

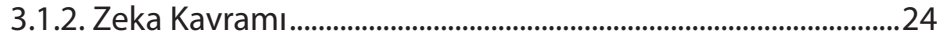

3.2. Duygusal Zekanın Tanımı ve Önemi ......................................................27

3.3. Duygusal Zekanın Tarihsel Gelişimi ..........................................................34

3.4. Duygusal Zeka Bileşenleri ..........................................................................37

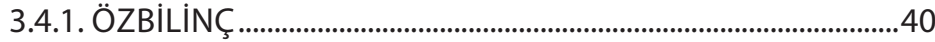

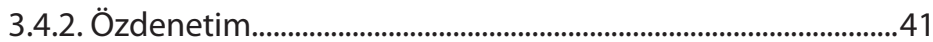

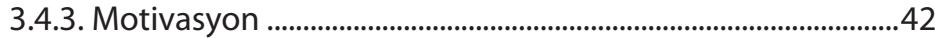

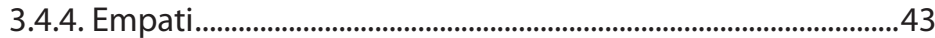

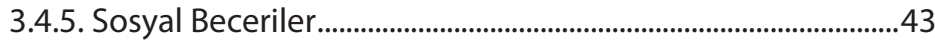

3.5. Duygusal Zeka Modelleri.........................................................................44

3.5.1. Mayer ve Salovey'in Duygusal Zekâ Modeli .............................44

3.5.2. Goleman'ın Duygusal Zekâ Modeli .............................................47

3.5.3. Bar-On Duygusal Zeka Modeli ......................................................47

3.4.4. Cooper ve Sawaf'ın Dört Köşe Taşı Modeli ..............................49

3.6. Diğer Zeka Türleri .........................................................................................52

3.6.1. Sosyal Zeka Kuramı ........................................................................52

3.6.2. Çoklu Zeka Kuramı ............................................................................53

3.6.3. Kültürel Zeka Kuramı ......................................................................54

4. IŞ TATMINI KAVRAMI VE KAPSAMI ..........................................55

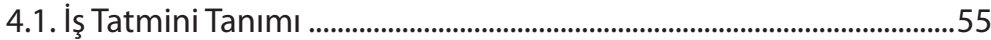

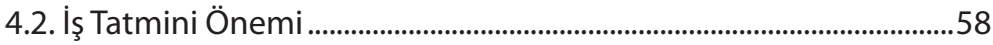


4. 3. İş Tatmini İle İlişki Kuramlar................................................................63

4.3.1. İhtiyaçlar Hiyerarşisi Kuramı ....................................................63

4.3.2. ERG Kuramı ..............................................................................65

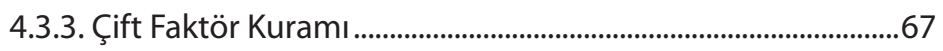

4.3.4. Başarı Gereksinimi Kuramı......................................................68

4.3.5. Vroom'un Beklenti Kuramı.........................................................69

4.3.6. Eşitlik Kuramı .............................................................................70

4.3.7. Cornell Kuramı ..........................................................................72

4.3.8. İş Özellikleri Kuramı...................................................................72

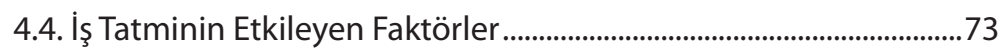

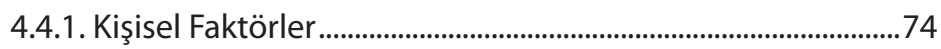

4.4.1.1. Cinsiyet...............................................................................74

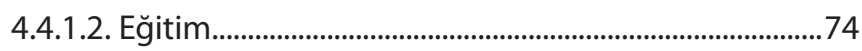

4.4.1.3. Kıdem ve Statü .................................................................... 75

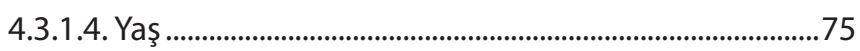

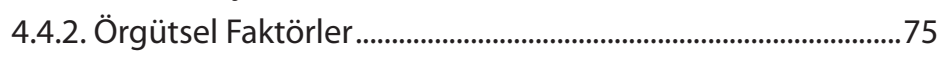

4.4.2.1. Çalışma Koşulları..............................................................76

4.4.2.2. Yükselme İmkanı.................................................................77

4.4.2.3. Ödül....................................................................................77

4.4.2.4. Denetim ve Çalışma Arkadaşları ..................................78

4.4.2.5. Ücret..................................................................................78

4.5. İş Tatminin Sonuçları ..............................................................................79

4.5.1. Bireysel Açıdan İş Tatmin Seviyesinin Sonuçları .....................80

4.5.2. Örgütsel Açıdan İş Tatmin Seviyesinin Sonuçları....................81

4.5.2.1. Performans ve Verimlilik .................................................81

4.5.2.2. Devamsızlık ........................................................................83

4.5.2.3. Personel Devir Hızı Üzerine Etkileri...............................84

\section{5. ÖRGÜTSEL BAĞLILIK KAVRAMI VE KAPSAMI .........................87}

5.1. Örgütsel Bağlılık Kavramı ve Tanımı .................................................87

5.2. Örgütsel Bağılıı İle İlişkili Diğer Kavramlar ......................................90

5.2.1. Mesleğe Bağlılık ...........................................................................91

5.2.2. İşe Bağlılık...............................................................................92

5.2.3. İş Arkadaşlarına Bağlılık..............................................................99

5.2.4. İş Tatmini .......................................................................................95 


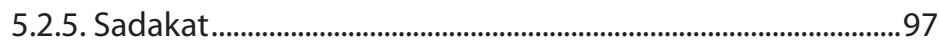

5.3. Örgütsel Bağlıı̆̆ın Göstergeleri ..........................................................98

5.3.1. Örgütün Amaç ve Değerlerini Benimseme ..............................99

5.3.2. Örgüt İçin Fedakârlıklarda Bulunabilme..................................99

5.3.3. Örgüt Üyeliğinin Devamı İçin Güçlü Bir İstek Duyma ..........99

5.3.4. Örgütle Özdeşleşme ................................................................. 100

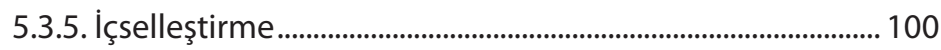

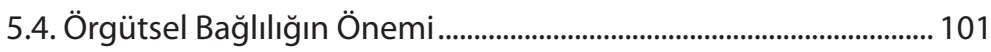

5.5. Örgütsel Bağlılık Yaklaşımları ......................................................... 102

5.5.1. Davranışsal Yaklaşım............................................................. 103

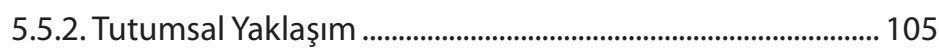

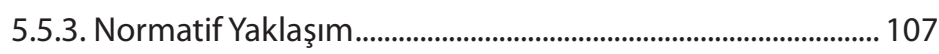

5.5.4. Çoklu Bağlııı Yaklaşımı ........................................................ 109

5.6. Örgütsel Bağlıı̆ğa Etki Eden Faktörler............................................... 109

5.6.1. Kişisel ve Demografik Faktörler .............................................. 110

5.6.1.1. İş Beklentileri.................................................................. 110

5.6.1.2. Psikolojik Sözleşme...................................................... 111

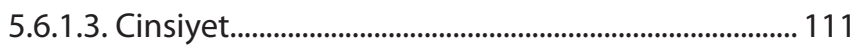

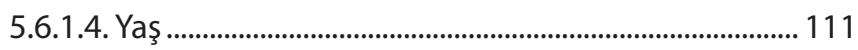

5.6.1.5. Medeni Durum ............................................................. 112

5.6.2. Örgütsel Faktörler................................................................... 113

5.6.2.1. İşin Niteliği ve Önemi................................................. 113

5.6.2.2.Çalışma Koşulları ve Süresi............................................ 114

5.6.2.3. Yönetim Şekli ve Liderlik.............................................. 115

5.6.2.4. Ücret Düzeyi.................................................................... 115

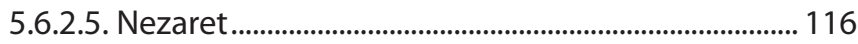

5.6.2.6. Örgüt Kültürü..................................................................... 117

5.6.2.7. Örgütsel Adalet ............................................................. 117

5.6.2.8. Örgütsel Ödüller ........................................................... 118

5.6.2.9. Takım Çalışması ............................................................ 118

5.6.2.10. Rol Belirsizliği ve Çatışma......................................... 119

5.6.3. Örgüt Dışı Faktörler ................................................................ 121

5.6.3.1. Profesyonellik ............................................................. 121

5.6.3.2. Yeni İş Bulma Olanakları............................................ 121

5.7. Örgütsel Bağlılık Türlerine Göre Örgütsel Bağlılık Faktörleri..... 122 
5.7.1. Duygusal Bağlılığa Etki Eden Faktörler 122

5.7.2. Devamlılık Bağlılığına Etki Eden Faktörler ............................. 124

5.7.3. Normatif Bağlılığa Etki Eden Faktörler ................................... 126

5.8. Örgütsel Bağlılık Düzeyleri................................................................ 126

6. ÖRGÜTSEL GÜVEN KAVRAMI VE KAPSAMI ........................... 129

6.1. Güven Kavramı ve Kapsamı ............................................................. 129

6.2. Örgütsel Güven Kavramı ve Kapsamı................................................ 134

6.3. Örgütsel Güvenin Boyutları ............................................................... 140

6.3.1. Yöneticiye Güven...................................................................... 140

6.3.2. Örgüte Güven ............................................................................... 142

6.3.3. Çalışma Arkadaşlarına Güven .................................................. 144

6.4. Örgütsel Güven ile İlgili Yaklaşımlar ve Modeller............................ 147

6.4.1. Bromiley ve Cummings Yaklaşımı ........................................... 147

6.4.2. Mayer, Davis ve Shoorman'ın Örgütsel Güven Modeli .... 148

6.4.3. Luhmann'ın Modeli .................................................................... 149

6.4.4. Jones ve George (1998) Modeli ............................................. 149

6.4.5. Likert'in Güven Modeli ............................................................. 150

6.4.6. McGregor'un Güven Modeli ................................................... 151

6.4.7. Argyris'in Güven Modeli ....................................................... 151

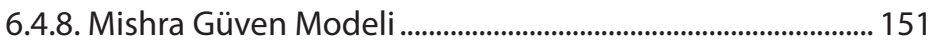

6.4.9. Caldwell ve Clapham Modeli ................................................ 152

6.5. Örgütsel Güvenin Faydaları ve Sonuçları........................................ 153

7. DUYGUSAL ZEKA VE iş TATMINi iLişKISINE ÖRGÜTSEL GÜVEN VE ÖRGÜTSEL BAĞLILIĞIN ARACILIK ROLÜNE İLIŞKIN BIIR ALAN ARAŞTIRMASI ........... 159

7.1. Araştırmanın Amacl .................................................................... 159

7.2. Araştırmanın Kapsamı ve Örneklemi............................................... 160

7.3. Araştırmanın Sınırları............................................................................. 160

7.4. Araştırmada Kullanılan Veri Toplama Araçları ................................. 161

7.5. Yapısal Eşitlik Modeli, Araştırmanın Modeli ve Hipotezleri........ 162

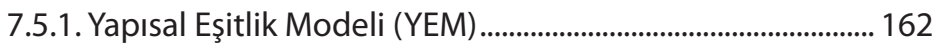

7.5.2. Model ve Hipotezler .................................................................. 165

7.6. Araştırmanın Bulguları ......................................................................... 166 
7.6.1. Demografik Değişkenler ile İlgili Tanımlayıcı İstatistikler. 166

7.6.2. Araştırma Modelinde Yer Alan Değişkenlerin Doğrulayıcı Faktör Analizi (DFA). 172

7.6.2.1. WLEI Ölçeği 173

7.6.2.2. Örgütsel Bağlılık Ölçeği 174

7.6.2.3. Örgütsel Güven Ölçeği .................................................. 176

7.6.2.4. İş Tatmini Ölçeği.......................................................... 177

7.7. Araştırma Modelinin Doğrulayıcı Faktör Analizi (DFA) 179

8. SONUÇ VE ÖNERILER 181

KAYNAKLAR 191

EKLER .227 


\title{
KISALTMALAR LISTESI
}

\author{
AMOS : Analysis of Moment Structures \\ HBR: $\quad$ : Harward Business Review \\ IQ: $\quad$ : Intelligence Quotient \\ İSO: : İstanbul Sanayi Odası
}

KMTSO: : Kahramanmaraş Ticaret ve Sanayi Odası

KOSGEB: : Küçük ve Orta Ölçekli İşletmeleri Geliştirme ve Destekleme İdaresi Başkanlığı

SPSS: $\quad$ : Statistical Package for the Social Sciences

WLEIS: : Wong And Law Emotional Intelligence Scale

YEM: : Yapısal Eşitlik Modeli 


\section{KAYNAKLAR}

ABRAHAM, R., 1997. “The Relationship of Vertical and Horizontal Indivualism and Collectivism to Intrapreneurship and Organizational Commitment", Leadership \& Organization Development Journal, 18(4), ss. 179-186.

ADİLOĞULLARI, İ., 2011. "Profesyonel Futbolcularda Duygusal Zekâ ile Örgütsel Bağlllık İlişkisi”, Doktora Tezi, Marmara Üniversitesi, İstanbul.

AFŞAR, L., 2013. “Örgütsel Sessizlik ve Örgütsel Güven İlişkisi: Konuya İliş̧kin Bir Araştırma”, Yüksek Lisans Tezi, İstanbul Üniversitesi, İstanbul.

AGHDASI, S., KIAMANESH, A. R. ve EBRAHIM, A. N., 2011. "Emotional Intelligence and Organizational Commitment: Testing the Mediatory Role of Occupational Stress and Job Satisfaction", Procedia-Social and Behavioral Sciences, 29, ss.1965-1976.

AKSOY, M., 2009. "İşletmelerde Örgütsel Güven Anlayışının Algılanması Ve Demografik Değişkenler Açısından Analizi”, Yüksek Lisans Tezi, Gazi Üniversitesi, Ankara.

ALAVI, S. Z., MOJTAHEDZADEH, H., AMIN, F. ve SAVOJI, A. P., 2013. "Relationship Between Emotional Intelligence and Organizational Commitment in Iran's Ramin Thermal Power Plant", Procedia-Social and Behavioral Sciences, 84, ss. 815-819.

ALDERFER, C. P., 1969. "An Empirical Test of a New Theory of Human Needs", Organizational Behavior and Human Performance, 4(2), ss. 142-175.

AL-HAMAMI, N. M., HASHIM, M. T., SONGIP, A. R. ve AL-SAEED, A. H., 2015. "The Effects of Emotional Intelligence on Job Satisfaction", Information and Knowledge Management, 5(6), ss. 98-101.

ALLEN, N. J. ve MEYER, J. P., 1990. “The Measurement and Antecedents of Affective, Continuance and Normative Commitment to the Organization", Journal of Occupational Psychology, 63(1), ss. 1-18.

AL-MEER, A. R., 1989. “Organizational Commitment: a Comparison of Westerns, Asians and Saudis", International Studies of Management and Organization, 19(2), ss. 51-62. 
ALNIDAWY, A. A. B., 2015. "The Effect of Emotional Intelligence on Job Satisfaction: Applied Study in the Jordanian Telecommunication Sector", International Journal of Business Administration, 6(3), ss. 63-71.

ALPARSLAN, E. ve ORHAN, K., 2016. “İşü̈cü Kaybının Nedenleri, Etkileri ve Alınabilecek Önlemler: Denizli Kablo ve Tel Üreticisi Bir Firmada Araştırma”, Çalışma İlişkileri Dergisi, 7(2), ss. 41-64.

ALTINTAŞ, Ö. C., 2009. "Duygusal Zekâ Elemanlarının Liderlik Tarzları ve Örgütsel Sonuçlar Üzerindeki Etkisi: Isparta İli İlköğretim Okullarında Bir Uygulama”, Doktora Tezi, Gebze Yüksek Teknoloji Enstitüsü, Gebze.

ALTUN, G., 2010. “Özel Eğitim Kurumlarında Çalışan Öğretmenlerin Örgütsel Güven Düzeyleri İle Örgütsel Bağlılıkları Arasındaki İlişkinin İncelenmesi”, Yayınlanmış Yüksek Lisans Tezi, Marmara Üniversitesi, İstanbul.

ANAND, R. ve UDAYASURIYAN, G., 2010. "Emotional Intelligence and Its Relationship with Leadership Practices", International Journal of Business and Management, 5(2), ss. 65-76.

ANG, S., VAN DYNE, L. ve KOH, C., 2006. "Personality Correlates of the Four-Factor Model of Cultural Intelligence", Group \& Organization Management, 31(1), ss. 100-123.

ANGLE, H. L. ve PERRY, J. L, 1981. "An Empirical Assessment of Organizational Commitment and Organizational Effectiveness", Administrative Science Quarterly, 26(1), ss. 1-13.

ARBAK, Y., ve KESKEN J., 2005. “Örgütsel Bağlllık, Sağlık Hizmetlerinde Sürekli Gelişim İçin Davranışsal Bir Yaklaşım”, Dokuz Eylül Üniversitesi Yayınları, İzmir, 186s.

ARI, S. G., 2005. "İşletmelerde Güven Ve Personel Güçlendirme İlişkisi (Bankacılık Sektöründe Bir Araştırma)”, Doktora Tezi, Hacettepe Üniversitesi, Ankara.

ARLI, D., 2011. “Öğretmenlerin Örgütsel Vatandaşlık Davranışlarının Örgüt Kültürü Algıları ve Örgütsel Güven Düzeyleri Açısından İncelenmesi, Doktora Tezi, Ege Üniversitesi, İzmir.

ARSLAN, Y., 2009. “Kurumsallaşma Ve Örgütsel Güven İlişkisi”, Yüksek Lisans Tezi, T.C. Gebze Yüksek Teknoloji Enstitüsü, Kocaeli. 
ASLAN, S. ve ÖZATA, M., 2008. "Duygusal Zekâ ve Tükenmişlik Arasindaki İlişkilerin Araştirilmasi: Saglik Çalişanlari Örneği”, Erciyes Üniversitesi İktisadi ve İdari Bilimler Fakültesi Dergisi, 30, ss. 77-97.

ASSANOVA, M. ve MCGUIRE, M. 2009. Applicability Analysis of the Emotional Intelligence Theory. Indiana University. Retrieved July, 21.

ASHRAF, M., NAWAZ, A., SHAIKH, O. A. ve BHATTI, S. R., 2014. "Emotional Intelligence and Job Satisfaction among Employees of Service Sector in Pakistan", International Journal of Innovative Research \& Development, 3(5), ss. 205-214.

ASUNAKUTLU, T. 2002. "Örgütsel Güvenin Oluşturulmasına İlişkin Unsurlar ve Bir Değerlendirme”, Muğla Üniversitesi Sosyal Bilimler Enstitüsü Dergisi, 9 (1), ss. 1-13.

ASUNAKUTLU, T., 2001. "Klasik ve Neo-Klasik Dönemde Örgütsel Güvenin Araştırılması Üzerine Bir Deneme”, Muğla Üniversitesi Sosyal Bilimler Enstitüsü Dergisi, 5, ss. 1-17.

AŞAN, E., 2007. Motivasyon. Ed.: Salih Güney, Yönetim ve Organizasyon, Nobel Yayın, Ankara, 736s.

AŞIK, D. A., 2010. “Çalışanların İş Doyumunu Etkileyen Bireysel ve Örgütsel Faktörler ile Sonuçlarına İlişkin Kavramsal bir Değerlendirme”, Türk İdare Dergisi, 467, ss. 31-51.

ATAK, M., 2009. “Öğrenen Örgüt ve Örgütsel Bağlllık İlişkisi”, Doktora Tezi, Atatürk Üniversitesi, Erzurum.

ATİLLA, G., 2012. "Hastanelerde Duygusal Zeka-Hasta Memnuniyeti İlişkisi: Isparta İl Merkezi Örneği”, Süleyman Demirel Üniversitesi, Isparta.

AVRAM, E., IONESCU, D. ve MINCU, C. L., 2015. "Perceived Safety Climate and Organizational Trust: the Mediator Role of Job Satisfaction", Procedia-Social and Behavioral Sciences, 187, ss. 679-684.

AZIRI, B., 2011. "Job Satisfaction: A Literature Review", Management Research and Practice, 3(4), ss. 77-86.

BABA, M. L., 1999. "Dangerous Liaisons: Trust, Distrust And Information Technology İn American Work Organization”. Human Organization, 58, ss. 331- 346.

BALAY, R., 2000. Yönetici ve Öğretmenlerde Örgütsel Bağlllık, Nobel Yayın Dağıtım, Ankara, 192s. 
BALCI, A., 1985. "Eğitim Yöneticisinin İş Doyumu”, Doktora Tezi, Ankara Üniversitesi, Ankara.

BALFOUR, D. L. ve WECHSLER B., 1996. “Organizational Commitment: Antecedents and Outcomes in Public Organizations", Public Productivity \& Management Review, 19(3), ss. 256-277.

BALTAŞ, Z., 2006. Duygusal Zeka, 3. Baskı, Remzi Kitabevi, İstanbul.

BAKAN, İ. Ve DOĞAN, İ. F., 2014. İnsan Kaynakları Yönetimi. Ed.: İsmail Bakan, Gazi Kitapevi, Ankara.

BARIŞ U. ve BEYCIOĞLU, K., 2013. “İlköğretim Okulu Öğretmenlerinin Örgütsel Bağl1lıkları ile Müdürlerin Paylaşılan Liderlik Rolleri Arasındaki İlişki”, On dokuz Mayıs Üniversitesi Eğitim Fakültesi Dergisi, 32(2), ss. 323-345.

BAR-ON, R., 1997. Emotional Quotient Inventory: Technical Manual. Multi Health Systems, Toronto.

2006. "The Bar-On Model of Emotional-Social Intelligence (ESI)”, Psicothema, 18, ss. 13-25.

BARUTÇUGİL, İ., 2004. Stratejik İnsan Kaynakları Yönetimi. Kariyer Yayınlcılık, İstanbul, 499s.

BASIM, N. ve ŞEŞEN, H., 2009. "Örgütsel Adalet Algısı-Örgütsel Vatandaşlık Davranışı İlişkisinde İş Tatmininin Aracılık Rolu”, Osman Gazi Üniversitesi 17. Yönetim ve Organizasyon Kongresi Bildiriler Kitab1, ss. 806-812.

BAŞARAN, E., 1994. Eğitim Psikolojisi: Modern Eğitimin Psikolojik Temelleri. Yargıcı Matbaasi, Ankara, 452s.

BAYRAM, L., 2005. "Yönetimde Yeni Bir Paradigma: Örgütsel Bağlll1k", Sayıştay Dergisi, 59(1), ss. 125-139.

BAYSAL, A. C., ve PAKSOY, M., 1999. "Mesleğe ve Örgüte Bağlılı̆̆ın Çok Yönlü İncelenmesinde Meyer-Allen Modeli”, İ.Ü.İşletme Fakültesi Dergisi, 28(l), ss. 7-15.

BELLİ E., 2010. “Ege Bölgesindeki Gençlik ve Spor İl Müdürlüklerinde Çalışan Personelin Örgütsel Bağlılıkları ve İş Tatmin Düzeylerinin Araştırılması”, Yüksek Lisans Tezi, Muğla Üniversitesi, Muğla.

2014. “Gençlik Hizmetleri ve Spor İl Müdürlüklerinde Çalışan Personelin Mobbing Düzeylerinin Araştırılması ve Bağlılık Yönünden Değerlendirilmesi”, Doktora Tezi, Atatürk Üniversitesi, Erzurum. 
BELTEKİN, E. ve ULUCAN, H., 2016. “Türkiye'deki Gençlik Hizmetleri ve Spor İl Müdürlüklerinde Görev Yapan Yönetici Personelin Duygusal Zekâ ve Örgütsel Bağlllık Düzeylerinin İncelenmesi”, Beden Egitimi ve Spor Bilimleri Dergisi, 10(2), ss. 257-269.

BENKHOFF, B., 1997. "Disentangling Organizational Commitment, The Dangers Of The OCQ for Research and Policy”, Personnel Review, 26(1-2), ss. 114-131.

BENNETT, H. ve DURKIN, M, 2000. “The Effects of Organisational Change on Employee Psychological Attachment: An Exploratory Study”, Journal of Managerial Psychology, 15(2), ss. 126-147.

BENTON, D. A., 1991. “Team Development” Consulting For Federal Agencies, AT\&Tand Small Businesses. Aktaran: Douglas Benton ve Jack Halloran, Applied Human Relations an Organizational Approach, New Jersey: Prentice-Hall..

BJÖRKQVİST, K., ÖSTERMAN, K. ve KAUKIAINEN, A., 2000. "Social Intelligence-Empathy-Aggression?”, Aggression and Violent Behavior, 5(2), ss. 191-200.

BLAU, G. J. ve BOAL, K. B., 1987. “Conceptualizing How Job Involvement and Organizational Commitment Affect Turnover and Absenteeizm", Academy of Management Review, 12(2), ss. 288-300.

BLAU, G. J., 1985. "The Measurement and Prediction of Career Commitment”, Journal of Occupational Psychology, 58(2), ss. 277-288.

BLAU, G. J. ve BOAL, K. B., 1987. "Conceptualizing How Job Involvement and Organizational Commitment Affect Turnover and Absenteeism", Academy of Management Review, 12 (2), ss. 288-300.

BOUWKAMP, J. C., 2008. "The Work Values And Job Satisfaction Of Family Physicians", PHD Thesis, Indiana University, Bloomington.

BOYATZIS, R. E. ve SALA, F., 2004. Assessing Emotional Intelligence Competencies. The Measurement of Emotional Intelligence, Nova Science Publishers, New York, 50s.

BÖKEOĞLU, Ö. Ç. ve YILMAZ, K. Y., 2008. “İlköğretim Okullarında Örgütsel Güven Hakkında Öğretmen Görüşleri”, Kuram ve Uygulamada Eğitim Yönetimi Dergisi, 54, ss. 211-233.

BROMILEY, P. ve CUMMINGS, L. L., 1996. “The Organizational Trust Inventory (OTI)", Trust in Organizations: Frontiers of Theory and Research, 302(330), ss. 39-52. 
BROWER, H. H., LESTER, S. W., KORSGAARD, M. A. ve DINEEN, B. R., 2009. "A Closer Look at Trust between Managers and Subordinates: Understanding the Effects of Both Trusting and Being Trusted on Subordinate Outcomes" Journal of Management, 35 (2), ss. 327-347.

BROWN, S.P., 1996. "A Meta-Analysis And Review Of Organizational Research On Job Involvement”, Psychological Bulletin, 120(2), ss. 235-255.

BUDAK, S., 2000. Psikoloji Sözlüğü, Bilim ve Sanat Yayınları, Ankara, $1013 \mathrm{~s}$.

BULUT, M., 2003. “Örgütsel Bağlllık”, Yüksek Lisans Tezi, Celal Bayar Üniversitesi, Manisa.

BUTLER, C. J. ve CHINOWSKY, P. S., 2006. "Emotional Intelligence and Leadership Behavior in Construction Executives", Journal of Management in Engineering, 22(3), ss. 119-125.

BYINGTON, J. R. ve JOHNSTON, J. G., 1991. "Influences on Turnover of Internal Auditors”, Internal Auditing, 7(2), ss. 3-10.

CALDWELL, C. ve CLAPHAM, S., 2003. "Organizational Trustworthiness: An International Perspective", Journal of Business Ethics, 47(4), ss. 349-364.

CALDWELL, C. ve HANSEN, M. H., 2010. “Trustworthiness, Governanceand Wealth Creation” Journal Of Business Ethics, 97, ss. 173-188.

CALlAWAY, P. L., 2006. "Relationship Between Organizational Trust and Job Satisfaction: An Analysis in the U.S. Federal Work Force", Phd Thesis, Capella University, Minneapolis.

CAM, E. 2004. "Çalışma Yaşamında Stres ve Kamu Kesiminde Kadın Çalışanlar”, Uluslararası İnsan Bilimleri Dergisi, ss. 1-10.

CAN, H., TUNCER, D. ve AYHAN, D. Y., 1984. İşletme ve Yönetim. Aşkunlar Matbaas1, Ankara.

CAPLAN, R. D. ve JONES, K. W., 1975. "Effects of Work Load, Role Ambiguity, and Type A Personality on Anxiety, Depression, and Heart Rate", Journal of Applied Psychology, 60(6), ss. 713-719.

CARUSO, D.R. ve SALOVEY, P., 2004. The Emotionally Intelligent Manager: How to Develop and Use the Four Key Emotional Skills of Leadership. John Wiley \& Sons, New York, 320s. 
CENGİZ, A. A., 2001. "Kişisel Özelliklerin Örgütsel Bağl1lık Üzerindeki Etkileri ve Eskişehir'de Sağlık Personeli Üzerinde Bir Uygulama”, Yüksek Lisans Tezi, Anadolu Üniversitesi, Eskişehir.

CEYLAN, A. 1998. Örgütsel Davranışın Bireysel Boyutu, GYTE Yayın, Gebze.

CEYLAN, A. ve ULUTÜRK, Y. H., 2006. "Rol Belirsizliği, Rol Çatışması, İş Tatmini ve Performans Arasındaki İlişkiler”, Doğuş Üniversitesi Dergisi, 7, ss. 48-58.

CHAMI, R. ve FULLENKAMP, C., 2002. “Trust And Efficiency”, Journal Of Banking \& Finance, 26, ss. 1785-1809.

CHANG, Y. H. ve WANG, Y. C., 2010. “Significant Human Risk Factors İn Aircraft Maintenance Technicians. Safety Science, 48(1), ss. 54-62.

CHEN, Z. X., TSUI, A. S. ve FARH, J. L., 2002. "Loyalty to Supervisor vs. Organizational Commitment: Relationship to Employee Performence in China", Journal of Occupational and Organizational Psychology, 75(1), ss. 339-356.

CHERRINGTON, D. J., 1983. Personnel Manegement: The Management of Human Resources, Dubugue, Iowa, 271s.

CHIANG, C. F. ve JANG, S. S., 2008. "An Expectancy Theory Model for Hotel Employee Motivation", International Journal of Hospitality Management, 27(2), ss. 313-322.

CHOWDHURY, S., 2005. "The Role of Affect- and Cognition-Based Trust in Complex Knowledge Sharing", Journal of Managerial Issues, 17(3), ss. 310-326.

CHRISTEN, M., IYER, G. ve SOBERMAN, D., 2006. "Job Satisfaction, Job Performance, and Effort: A Reexamination Using Agency Theory", Journal of Marketing, 70(1), ss. 137-150.

CHUSMIR, L. H., 1982. "Job Commitment and Organizational Woman", Academy of Management Review, 7(4), ss. 271.

CODIER, E., FREITAS, B. ve MUNENO, L., 2013. "Developing Emotional Intelligence Ability in Oncology Nurses: A Clinical Rounds Approach", Oncology Nursing Forum, 40(1), ss. 22-29.

COHEN, A., 1992. "Antedecetents of Organizationasl Commitment Across Occupational Groups: A Meta Analysis", Journal of Organizational Behavior, 13(1), ss. 539-554. 
1993. "Age and Tenure in Relation to Organizational Commitment: A Meta-Analysis", Basic and Applied Social Psychology, 14 (2), ss. 143-159.

COLE, M. L., COX, J. D. ve STAVROS, J. M., 2016. “Building Collaboration in Teams Through Emotional Intelligence: Mediation by SOAR (Strengths, Opportunities, Aspirations, and Results)", Journal of Management \& Organization, ss. 1-21.

COOK, J. ve WALL, T., 1980. "New Work Attitude Measures of Trust, Organizational Commitment and Personal Need Non-Fulfilment", Journal of Occupational Psychology, 52, ss. 39-52.

COOPER, R.K. ve SAWAF, A., 2003. Liderlikte Duygusal Zeka, Sistem Yayınc1lık, İstanbul, 480s.

COPE, M., 2003. Yürek Beyin ve El. BZD Yayıncilık, İstanbul, 199s.

CRANNY, C. J., SMITH, P. C. ve STONE, E. F. (Eds.), 1992. Job Satisfaction: How People Feel about Their Jobs and How It Affects Their Performance. Lexington Books, 296s.

CUMMING, E.A., 2005. "An Investigation into the Relationship Between Emotional Intelligence and Workplace Performance: An Exploratory Study", Phd Thesis, Lincoln University, Pennsylvania.

CÜCE, H., GÜNEY, S. ve TAYFUR, Ö., 2013. “Örgütsel Adalet Algılar1nın Örgütsel Özdeşleşme Üzerindeki Etkisini Belirlemeye Yönelik Bir Araştırma", Hacettepe Üniversitesi İktisadi ve İdari Bilimler Fakültesi Dergisi, 31(1), ss.1-30.

ÇAĞLAR, Ç., 2011. “Okullardaki Örgütsel Güven Düzeyi İle Öğretmenlerin Mesleki Tükenmişlik Düzeyinin Bazı Değişkenler Açısından İncelenmesi”, Kuram ve Uygulamada Eğitim Bilimleri Dergisi, 11 (4), ss. 1827-1847.

ÇAKAR, U. ve ARBAR, Y., 2004. "Modern Yaklaşımlar Işı̆̆ında Değişen Duygu-Zeka İlişkisi ve Duygusal Zeka”, DEU Sosyal Bilimler Enstitüsü Dergisi, 6(3), ss. 23-48.

ÇAKIR, Ö., 2001. "Yeni Çalışma Biçimleri ve İşe İlişkin Tutumlar”, Endüstri İlişskileri ve İnsan Kaynakları Dergisi, 3(1), ss. 106-123.

ÇAKMAK, H., 2008. "Kurumsal İmajın Çalışanların Örgütsel Bağlılıkları Üzerindeki Etkisine Yönelik Bir Araştırma”, Yüksek Lisans Tezi, Dumlupınar Üniversitesi, Kütahya. 
ÇARIKÇI, İ. H., 2000. “Çalışanların İş Tatminlerini Etkileyen Kişisel Özellikler: Süpermarket Çalışanları Üzerinde Bir Araştırma”, Süleyman Demirel Üniversitesi İktisadi İdari Bilimler Fakültesi Dergisi, 5(2), ss. 155-168.

ÇEKMECELİĞLU, H. G., GÜNSEL, A. ve ULUTAŞ, T., 2012. “Effects of Emotional Intelligence on Job Satisfaction: An Empirical Study on Call Center Employees", Procedia-Social and Behavioral Sciences, 58, ss. 363-369.

ÇELEN, Ö., TEKE, A. ve CİHANGİROĞLU, N., 2013. “Örgütsel Bağl111ğın İş Tatmini Üzerine Etkisi: Gülhane Askeri Tip Fakültesi Eğitim Hastanesinde Bir Araştırma”, Süleyman Demirel Üniversitesi İktisadi ve İdari Bilimler Fakültesi Dergisi, 18(3), ss. 399-410.

ÇELİK, M., TURUNÇ, Ö. ve BEĞENİRBAŞ, M., 2011. “Örgütsel Performansın Sağlanmasında Örgütte Güven, Tükenmişlik ve Kişiler Arası Çarpıklığın Rolü” Cag University Journal of Social Sciences, 8(1), ss. 1-29.

ÇETİN, M. Ö., 2004. Örgüt Kültürü ve Örgütsel Bağlllık, Nobel Yayın Dağıtım, Ankara, 150s.

ÇETINNEL, E., 2008. “Örgütsel Güven ile Örgütsel Bağlllık Arasındaki İlişki Üzerine Bir Araştırma», Yüksek Lisans Tezi, Sakarya Üniversitesi, Sakarya.

ÇİÇEK, H. ve MACİT, N. Ş., 2016. "Konaklama İşletmelerinde Çal1şanların Örgütsel Güveni İle İş Tatmini Arasındaki İlişkinin İncelenmesi-Examining The Relationship Between Organizational Trust And Job Satisfaction Of Employees In Hospitality Business", Mehmet Akif Ersoy Üniversitesi Sosyal Bilimler Enstitüsü Dergisi, 8(14), ss. 25-41.

ÇİMEN, M. A., 2009. "Polis Meslek Yüksek Okullarında Örgüt Kültürü Oluşumunda Örgüt İçi İletişimin Rolü ve Önemi”, Fırat Üniversitesi Sosyal Bilimler Enstitüsü Eğitim Yönetimi, Teftişi, Planlaması ve Ekonomisi Ana Bilim Dalı, Elazığ.

ÇOLAK, M. ve ERDOST, H. E., 2004. “Organizational Justice: A Review of The Literature and Some Suggestions For Future Research", Hacettepe Üniversitesi İktisadi ve İdari Bilimler Fakültesi Dergisi, 22(2), ss. 51-84. 
ÇÖL, G. ve ARDIÇ, K., 2008. "Sosyal Yapısal Özelliklerin Örgüte Bağl1lık Üzerine Etkileri”, GOP İktisadi ve İdari Bilimler Dergisi, 21(2), ss. $157-174$.

DAILEY, R. C. ve KIRK, D. J., 1992. "Distrubutive and Procedural Justice as Antecedents oj Job Dissatisfaction and Intend to Turnover", Human Relations, 45(3), ss. 305-317.

DAVIS, J. W., 2006. "Emotional Intelligence as a Predictor of Career Longevity Among Special Education Teachers in the Houston County, Georgia, School System", Phd Thesis, Georgia Southern University, Georgia.

DAVIS, K. ve NEWSTROM, J. W., 1989. Human Behavior at Work, Organizational Bahavior. Eight Edition, McGraw Hill Book Company, New York, 179s.

DECONINCK, J. B., 2010. “The Effect of Organizational Justice, Perceived Organizational Support, and Perceived Supervisor Support on Marketing Employees' Level of Trust", Journal Of Business Research, 63, ss. 1349-1355.

DECOTIIS, T. A. ve SUMMERS, T. P., 1987. "A Path Analysis of a Model of The Antecedents and Consequences of Organizational Commitment", Human Relations, 40(7), ss. 445-470.

DELHEY, J. ve NEWTON., K. 2003. “Who Trusts?” European Societies, 5(2), ss. 93-137.

DEMİR, M., 2010. “Örgütsel Çatışma Yönetiminde Duygusal Zekanın Etkisi: Konaklama İşletmelerinde İşgörenlerin Algılamaları Üzerine Bir Araştırma”, Doğuş Üniversitesi Dergisi, 11(2), ss. 199-211.

DEMİR, S. E., 2011. “Örgütsel Güven, Örgütsel Bağlllık Ve İş Tatmininin Çalışanlar Açısından Algısı: Kahramanmaraş Tekstil Sektöründe Bir Araştırma”, Yüksek Lisans Tezi, Kahramanmaraş Sütçü İmam Üniversitesi, Kahramanmaraş.

DEMİRCAN, N. ve CEYLAN, A., 2003. "Örgütsel Güven Kavramı: Nedenleri ve Sonuçları”, Celal Bayar Üniversitesi İİB Yönetim ve Ekonomi Dergisi, 10(2), ss. 139-150.

DEMİREL, Y., 2008. “Örgütsel Güvenin Örgütsel Bağlll1k Üzerine Etkisi: Tekstil Sektörü Çalışanlarına Yönelik Bir Araştırma”, Yönetim Ve Ekonomi, 15(2), ss. 179-194. 
DEVELİOĞLU, K. ve ÇİMEN, M., 2012.” Örgütsel Güvenin Kaynağ Olarak İşletmelerin Çalışanlara Karşı Sosyal Sorumlulukları", Uluslararası Alanya İşletme Fakültesi Dergisi, 4(2), ss. 141-149.

DİCLE, A., 1986. Örgütsel Verimlilik ve Etkinlik. Türkiye Ortadoğu Amme İdaresi Enstitüsü, Ankara.

DIRKS, K. T. ve FERRIN, D. L., 2002. “Trust in Leadership: Meta-Analytic Findings and Implications for Research and Practice", Journal of Applied Psychology, 87(4), ss. 611-628.

DOĞAN, S., 2005. Çalışan İlişkileri Yönetimi. Kare Yayınları, İstanbul, $496 s$.

DOĞAN, S., ve KILIÇ, S., 2007. “Örgütsel Bağlılı̆̆ın Sağlanmasında Personel güçlendirmenin Yeri ve Önemi”, Erciyes Üniversitesi İktisadi ve İdari Bilimler Fakültesi Dergisi, 29, ss. 37-61

DOLU, B., 2011. "Bankacılık Sektöründe Çalışanların Örgütsel Bağlılık Düzeyleri Üzerine Bir Araştırma” Yüksek Lisans Projesi, Süleyman Demirel Üniversitesi, Isparta.

DOUGLAS A. B., 1991. “Team Development” Consulting For Federal Agencies, AT\&Tand Small Businesses. Aktaran: Douglas Benton Ve Jack Halloran, Applied Human Relations An Organizational Approach, New Jersey: Prentice-Hall, 350.

DÖKMEN, Ü., 2000. Varolmak Gelişmek Uzlaşmak. Remzi Kitapevi, İstanbul, 312s.

DRISCOLL, J. W., 1978. "Trust and Participation in Organizational Decision Making as Predictors of Satisfaction”, Academy of Management Journal, 21(1), ss. 44-56.

DUBIN, R, CHAMPOUX, J. E. ve PORTER, L. W., 1975. “Central Life Interests and Organizational Commitment of Blue-Collar and Clerical Workers", Administrative Science Quarterly, 20(7), ss. 411-421.

DURDAĞ, F. M. ve NAKTIYOK, A., 2011. "Psikolojik Taciz Algısının Örgütsel Güven Üzerindeki Rolü”, Kafkas Üniversitesi İ.İ.B.F. Dergisi, 1(2), ss. 5-37.

DUTOĞLU, G. ve TUNCEL, M., 2008. “Aday Öğretmenlerin Eleştirel Düşünme Eğilimleri ile Duygusal Zeka Düzeyleri Arasındaki İlişki”, Abant İzzet Baysal Üniversitesi Eğitim Fakültesi Dergisi, 8(1), ss.11-32. 
EALIAS, A. ve GEORGE, J., 2012. "Emotional Intelligence and Job Satisfaction: a Correlational Study", Research Journal of Commerce and Behavioral Science, 1(4), ss. 37-42.

EDVARDSSON, B., ve GUSTAVSSON, B., 2003. "Quality in The Work Environment: A Prerequisite for Success in New Service Development", Managing Service Quality, 13(2), ss. 148-163.

EĞRİBOYUN, D., 2013. “Ortaöğretim Okullarında Görev Yapan Yönetici Ve Öğretmenlerin Örgütsel Güven, Örgütsel Destek Ve Örgütsel Bağllıkkları Arasındaki İlişki (Bolu İli Örneği)", Doktora Tezi, Abant İzzet Baysal Üniversitesi, Bolu.

ELLIS, K. ve PAMELA, S. Z., 2001. “Trust in Top Management and Immediate Supervisor. The Relationship to Satisfaction, Perceived Organizational Effectiveness, and Infarmation Receiving", Comminication Quarteryl, 49(4), ss. 382-398.

ELNAGA, A. A. ve IMRAN, A., 2014. "The Impact of Employee Empowerment on Job Satisfaction Theoretical Study", American Journal of Research Communication, 2(1), ss. 13-26.

EMİRCAN, N., 2003. “Örgütsel Güven Kavramı: Nedenleri ve Sonuçlar1”, Yönetim ve Ekonomi, 10(2), ss. 139-150.

ENGİZEK, S., 2011. “Örgütsel Güven, Örgütsel Bağlllık ve İş Tatmininin Çalışanlar Açısından Algısı: Kahramanmaraş Tekstil Sektöründe Bir Araştırma”, Yüksek Lisans Tezi, Kahramanmaraş Sütçü İmam Üniversites, Kahramanmaraş.

ERDEM, A. F., 2003. “Örgütsel Yaşamda Güven”, Sosyal Bilimlerde Güven, Erdem, F., Ed., Vadi, Ankara, ss.153-183.

ERDEN, A., 2007. "Ankara Ve Lefkoşa Okul Yöneticilerinin Ve Öğretmenlerinin Örgütsel Güvene İlişkin Görüşleri”, Doktora Tezi, Ankara Üniversitesi, Ankara.

ERDIL, O., KESKIN, H., IMAMOGLU, S. Z. ve ERAT, S., 2004. "Yönetim Tarzı ve Çalışma Koşulları, Arkadaşlık Ortamı ve Takdir Edilme Duygusu ile İş Tatmini Arasındaki İlişkiler: Tekstil Sektöründe Bir Uygulama”, Doguş Üniversitesi Dergisi, 5(1), ss. 17-26.

ERDOGAN, İ., 1996. İşletme Yönetiminde Örgütsel Davranış. İşletme Fakültesi Yayınları, İstanbul, 333s.

1994. İşletmelerde Davranış, Beta Basım Yayım, İstanbul. 
2003. "Brain Drain and Turkey, Educational Sciences: Theory \& Practice", 3(1), ss. 96-100.

ERDOĞAN, M., 2015. "Psikolojik Sözleşme İhlali Algısının Örgütsel Sinizm ve Örgütsel Bağlılık Üzerine Etkisi: Konaklama İşletmelerinde Bir Uygulama”, Doktora Tezi, Atatürk Üniversitesi, Erzurum.

EREN, E., 2007. Örgütsel Davranı̧s ve Yönetim Psikolojisi, 7.Baskı, Beta Yayınları, İstanbul.

2010. Örgütsel Davranış ve Yönetim Psikolojisi. Beta Basım, İstanbul.

2015. Örgütsel Davranış ve Yönetim Psikolojisi. 15. Baskı, Beta Yayınlar1, İstanbul, 642s.

ERKUŞ, A., 1998. “Goleman’ın Duygusal Zeka Görüşünün Psikometrik Açıdan Eleştirisi ve Dinamik Etkileşimsel Model Önerisi”, Türk Psikoloji Yazıları Dergisi, 1(1), ss. 31-40.

EROĞLU, F., 2010. Davranış Bilimleri. Beta Yayınları, İstanbul, 567s.

ERONAT, Z., 2004. “İşletmelerde İş Tatmini ve İşüucü Devir Hızı Problemlerinin Çözümünde Bir Faktör Olarak İletişim; Kobi'lerde Ampirik Bir Uygulama”, Yüksek Lisans Tezi, Ankara Üniversitesi, Ankara.

FENIGSTEIN, A. ve VANABLE, P. A., 1992. "Paranoia and Self-Consciousness", Journal of Personality and Social Psychology, 62, ss. 129-138.

EVERJOBS, 05.05.2017, https://www.everjobs.com.bd/en/job-journal/ career-advice/the-importance-of-job-satisfaction/

FIELDS, D. L. ve BLUM, T. C., 1997. "Employee Satisfaction in Work Groups with Different Gender Composition”, Journal of Organizational Behavior, ss. 181-196.

FRAJO-APOR, B., KEMMLER, G., PARDELLER, S., PLASS, T., MUHLBACHER, M., WELTE, A. S., ... ve HOFER, A., 2017. Emotional Intelligence and Non-Social Cognition in Schizophrenia and Bipolar I Disorder”, Psychological Medicine, 47(1), ss. 35-42.

FUKAMI, C. V. ve LARSON, E. W., 1984. “Commitment to Company and Union; Parallel Models", Journal of Applied Psychology, 69(3), ss. $367-371$.

GALFORD, R. ve DRAPEAU, A. 2003. “The Enemies of Trust”, Harvard Business Review, 81 (2), ss. 88-95. 
GALLIE, D., FIELSTEAD, D., ve GREEN, F., 2001. "Employer Policies And Organizational Commitment in Britain”, Journal Of Management Studies, 38(8), ss. 1082-1103.

GENÇ, N., 2005. Yönetim ve Organizasyon. Seçkin Yayıncılık, Ankara, 416s.

GEZEGEN, S., 2010. "İş Güvencesizliği Algısı ve Örgütsel Güven Arasındaki İlişki: Bir Mobilya İşletmesinde Alan Araştırması”, Yüksek Lisans Tezi, Kocaeli Üniversitesi, Kocaeli.

GHOREISHI, F. S., ZAHIRRODINE, A. R., ASSARIAN, F., MOOSAVI, S. G. A. ve MEHRIZI, M. Z. Z., 2014. "Evaluation of Emotional Intelligence and Job Satisfaction in Employees of Kashan Hospitals", Nursing and Midwifery Studies, 3(1), ss. 1-6.

GILLILAND, S. W. ve CHAN, D., 2009. Örgütsel Adalet: Teori, Yöntemler ve Uygulamalar, Endüstri, İş ve Örgüt Psikolojisi El Kitabı, (Editör: N. Anderson, D.S. Öneş, H.K. Sinangir, C.Viswesvaran). Cilt 2, Literatür Yayıncılık: İstanbul, ss. 167- 194.

GLISSON, C. ve DURRICK, M, 1988. "Predictors of Job Satisfaction and Organizational Commitment in Human Service Organizations", Administrative Science Quarterly, 33(1), ss. 61-81.

GOLEMAN, D., 1995. Duygusal Zeka Neden IQ'dan Daha Önemlidir?. Çev.: Banu Seçkin Yüksel, Varlık Yayınları, İstanbul, 437s.

1998. Working with Emotional Intelligence. Bantam. 383s.

2006. Sosyal Zeka. Çev.: Banu Seçkin Yüksel, Varlık Yayınları, İstanbul, $488 \mathrm{~s}$.

2001. "Emotional Intelligence: Issues in Paradigm Building", Consortium for Research on Emotional Intelligence in Organizations, http:// www.eiconsortium.org/ (01.02.2017).

GOLEMAN, D., BOYATZIS, R. E. ve MCKEE, A., 2002. The New Leaders: Transforming the Art of Leadership into the Science of Results. Little, Brown, London.

2001. "Primal Leadership: The Hidden Driver of Great Performance", Harvard Business Review, 79(11), ss. 42-53.

GOOD, L. K, SISLER, G. F. ve GENTRY, J. W., 1989. “Antecedents Turnover Intentions Among Retail Management Personnel”, Journal of Retailing, 64(3), ss. 295-314. 
GÖÇ, K., 2012. “Örgütlerde Bilgi ve Bilgi Paylaşımında Örgütsel Bağlllığın Rolü Üzerine Bir Araştırma”, Yüksek Lisans Tezi, Aksaray Üniversitesi, Aksaray.

GÖKMEN, S., 1996. "İşletmeye Bağlllık Anketini Türkçeye Uyarlama ve Geçerlik ve Güvenirlilik Katsayılarını Belirleme Çalışması”, Yüksek Lisans Tezi, Hacettepe Üniversitesi, Ankara.

GREEN, J., 2000. Job Satisfaction of Community College Chairpersons. Virginia Polytechnic Institute and State University.

GROOT, W. ve BRINK, H.M., 1999. "Job Satisfaction Of Older Workers", International Journal Of Manpower, 20(6), ss. 343-360.

GROSS, J., 1998. "The Emerging Field of Emotion Regulation: An Integrative Review”, Review of General Psychology, 2, ss. 271-299.

GÜL, H., 2002, "Örgütsel Bağllılı Yaklaşımlarının Mukayesesi Ve Değerlendirmesi” Ege Akademik Bakış Online Dergi, 1(2), ss. 37-56.

GÜL, H., İNCE, M. ve KORKMAZ, O. 2014. “Çalışma Yaşamında Duygusal Zeka ve Bireylerin Duygusal Zeka Düzeylerini Kullanabilme Becerileri Üzerine Bir Araştırma”, Çağ Üniversitesi Sosyal Bilimler Dergisi, 11(1), ss. 30-49.

GÜlERYÜZ, G., GÜNEY, S., AYDIN, E. M. ve AŞAN, Ö., 2008. “The Mediating Effect of Job Satisfaction between Emotional Intelligence and Organisational Commitment of Nurses: A Questionnaire Survey", International Journal of Nursing Studies, 45(11), ss. 1625-1635.

GÜLLÜCE, A. Ç. ve İŞCAN, Ö. F., 2010. “Mesleki Tükenmişlik ve Duygusal Zekâ Arasındaki İlişki”, Eskişehir Osmangazi Üniversitesi İ̇̈F Dergisi, 5(2), ss. 7-29.

GÜMÜŞ, H,. 2010. "Liderlik Ve Örgütsel Güven Arasındaki İlişkinin Belirlenmesine Yönelik Bir Araştırma”, Yüksek Lisans Tezi, Dumlupınar Üniversitesi, Kütahya.

GÜNAYDIN, S. C., 2001. “İşletmelerde Örgütsel Adalet ve Örgütsel Güven Değişkenlerinin Politik Davranış Algısı ve İşbirliği Yapma Eğilimine Etkisini İnceleyen Bir Çalışma”, Yüksek Lisans Tezi, Marmara Üniversitesi, İstanbul.

GÜNDOĞAN, T., 2009. “Örgütsel Bağl1lı: Türkiye Cumhuriyeti Merkez Bankası Uygulaması” Uzmanlık Yeterlilik Tezi ,Türkiye Cumhuriyeti Merkez Bankası İnsan Kaynakları Genel Müdürlüğü, Ankara. 
GÜNEY, S., 2001. Stres ve Stresle Başa Çıkma. Ed.: Salih Güney, Yönetim ve Organizasyon, Nobel Yayın Dağıtım, Ankara, 580s.

2007. Yönetim ve Organizasyon. Ed.: Salih Güney, Nobel Yayın Dağıtım, Ankara,736s.

2012. Liderlik. Nobel Yayın Dağıtım, Ankara,448s

GÜRBÜZ, S. ve YÜKSEL, M., 2008. "Çalışma Ortamında Duygusal Zeka: İş Performansı, İş Tatmini, Örgütsel Vatandaşlık Davranısı ve Bazı Demografik Özelliklerle İlişkisi”, Doguş Üniversitesi Dergisi, 9(2), ss. 174-190.

HACKMAN, J. R. ve OLDHAM, G. R., 1975. "Development of the Job Diagnostic Survey", Journal of Applied Psychology, 60(2), ss. 159170.

1976. "Motivation Through the Design of Work: Test of a Theory", Organizational Behavior and Human Performance, 16, ss. 250-279.

HALİS, M., GÖKGÖZ, S. G. ve YAŞAR Ö., 2007. “Örgütsel Güvenin Belirleyici Faktörleri Ve Bankacılık Sektöründe Bir Uygulama”, Sosyal Bilimler Dergisi, 17, ss. 187-205.

HALSEY, W,. 1988. Macmillan Contemporary Dictionary, ABC Tanıtım Basımevi, 1. Baskı, İstanbul, 1157s.

HBR (Harward Business Rewiew), 2016. Duygusal Zeka. Çev.: Ş. Ümit, Optimist Yayın Dağıtım, İstanbul, 224s.

HEIN, S., 2005. Wayne Payne's 1985 Doctoral Paper on Emotions and Emotional Intelligence. Retrieved November 21.

HERZBERG, F., 1976. The Managerial Choice: To Be Efficient and to Be Human. Irwin Professional Publishing.

HERZBERG, F., MAUSNER, B. ve SNYDERMAN, B. B., 1959. The Motivation to Work. John Wiley \& Sons. Inc., New York.

HICKSON, C. ve OSHAGBEMI, T., 1999. "The Effect of Age on the Satisfaction of Academics with Teaching and Research", International Journal of Social Economics, 26 (4), ss. 537-544.

HOOFF, B. V. D. ve RIDDEN, J. A. D., 2004. “Knowledge Sharing in Context: The Influence of Organizational Commitment, Communication Climate and CMC Use on Knowledge Sharing," Journal of Knowledge Management, 8(6), ss.13-24. 
HOPPOK, R. S. ve SPIELGLER, S., 1938. “Job Satisfaction”, Occupations: The Vocational Guidance Journal, 16(7), ss. 636-643.

HOUSE, R. J. ve WIGDOR, L. A., 1967. "Herzberg's Dual-Factor Theory of Job Satisfaction and Motivation: A Review of the Evidence and a Criticism", Personnel Psychology, 20(4), ss. 369-390.

HOWE, D., 2008. The Emotionally Intelligent Social Worker. Palgrave Macmillan, New York, 208s.

HREBINIAK, L. G. ve ALUTTO, J. A., 1972. "Personal and Role-Related Factors in the Development of Organizational Commitment", Administrative Science Quarterly, 17(3), ss. 555-572.

USTA, I. ve KÜÇÜKALTAN, D., 2012. “Ödüllendirmenin Örgütsel Bağlılığa Etkisi: İstanbul'daki Beş Yıldızlı Otel İşletmelerinde Bir Araştırma”, Ekonomi ve Yönetim Araştırmaları Dergisi, 1(2), ss. 71-89.

IZGAR, H., 2008. "Okul Yöneticilerinde İş Doyumu ve Örgütsel Bağl1lık”, Ahmet Keleşoğlu Eğitim Fakültesi Dergisi, 25, ss. 317-334.

İBİCIOĞLU, H., 2000. “Örgütsel Bağlllıkta Paradigmatik Uyumun Yeri”, Dokuz Eylül Üniversitesi, İ. İ. B. F. Dergisi, 15(l), ss. 13-22.

İÇERLİ, L., 2010. “Örgütsel Adalet: Kuramsal Bir Yaklaşım”, Girişimcilik ve Kalkınma Dergisi, 5(1), ss.67-92.

İLHAN, M. ve ÇETİN, B., 2014. "Kültürel Zekâ Ölçeğinin Türkçe Formunun Geçerlik ve Güvenirlik Çalışması”, Hacettepe Üniversitesi Eğitim Fakültesi Dergisi, 29(2), ss. 94-114.

İNCE, M., ve GÜL, H., 2005. Yönetimde Yeni Bir Paradigma: Örgütsel Bağllık, Çizgi Kitapevi, Konya, 122s.

İNCİR, G., 1990. Çalışanların İş Doyumu Üzerine Bir İnceleme. Milli Prodüktivite Merkezi Yayınları, Ankara, 79s.

İŞCAN, Ö. F. ve SAYIN, U., 2010. “Örgütsel Adalet, İş Tatmini ve Örgütsel Güven Arasındaki İlişki”, Atatürk Üniversitesi İktisadi ve İdari Bilimler Dergisi, 24(4), ss. 195-216.

JAEGER, A. J., 2003. "Job Competencies and the Curriculum: An Inquiry Into Emotional Intelligence in Graduate Professional Education", Research in Higher Education, 44(6), ss. 615-639.

JANİĆİEVİĆ, N., KOVAČEVİ́, P. ve PETROVİĆ, I., 2015. “Identifying Organizational Factors of Job Satisfaction: The Case of One Serbian Company", Economic Annals, 60(205), ss. 73-104. 
JONES, G. ve GEORGE, J., 1998. “The Experience And Evolutiorf ; Trust, Implications For Cooperation And Teamwork", Academy Of Management Review, 23(3), ss. 531-46.

JOSEPH, E. E. ve WINSTON, B. E., 1996. "A Correlation of Servant Leadership, Leader Trust, and Organizational Trust”, Leadership \& Organization Development Journal, 26 (1), ss. 6-22.

KAFETSIOS, K. ve LOUMAKOU, M., 2007. "A Comparative Evaluation of the Effects of Trait Emotional Intelligence and Emotion Regulation on Affect at Work and Job Satisfaction", International Journal of Work Organization and Emotion, 2(1): ss. 71-87.

KAFETSIOS, K. ve ZAMPETAKIS, L. A., 2008. "Emotional Intelligence and Job Satisfaction: Testing the Mediatory Role of Positive and Negative Affect at Work". Personality and Idividual Differences, 44(3), ss. 712-722.

KAHYA, C., 2013. "Dönüştürücü ve Etkileşimci Liderlik Anlayışları İle Örgütsel Sessizlik Arasındaki İlişkide Örgütsel Güvenin Rolü”, Doktora Tezi, Atatürk Üniversitesi, Erzurum.

KALISKI, S. B., 2007. Encyclopedia of Business and Finance. Thompson Gale, Detroit.

KALLEBERG, A. L. ve REVE, T, 1992. "Contracts and Commitment: Economic and Sociological Perspectives on Employment Relations", Human Relations, 45(9), ss. 1100-1131.

KAMER, M., 2001. “Örgütsel Güven, Örgütsel Bağlllık ve Örgütsel Vatandaşlık Davranışlarına Etkileri”, Yüksek Lisans Tezi, Marmara Üniversitesi, İstanbul.

KARKIN, N., 2004. "Kamu ve Özel Sektör Yöneticilerinin Liderlik Davranışları”, Türk İdare Dergisi, 76(445), ss. 43-84.

KARRASCH, A. I., 2003. "Antecedents and Consequences of Organizational Commitment”, Military Psychology, 15(3), ss. 225-236.

KATZ, D. ve KAHN, R. L, 1977. Örgütlerin Toplumsal Psikloljisi, Çev: H. Can ve Y. Bayar, TODAİE Yayınları, Ankara, 217s.

KAUKIAINEN, A., BJÖRKQVIST, K., LAGERSPETZ, K., ÖSTERMAN, K., SALMIVALLI, C., ROTHBERG, S. ve AHLBOM, A., 1999. “The Relationships between Social Intelligence, Empathy, and Three Types of Aggression", Aggressive Behavior, 25(2), ss. 81-89. 
KAVI, A., 1998. "Relationship Between Organizational Commitment and Organizational-Professional Conflict", The Case of Electrical Engineers in Turkey, Yüksek Lisans Tezi, ODTÜ, Ankara.

KAYA, F. ve PEKER, A., 2016. "Üniversite Öğrencilerinin Affetme ve Mükemmeliyetçilik Düzeyleri Arasındaki İlişki: Duygusal Zekânın Aracı Rolü’, University of Gaziantep Journal of Social Sciences, 15(4), ss. 1086-1094.

KAYIŞ, A., 2005. Güvenilirlik Analizi. Ed.: Ş. Kalaycı, SPSS Uygulamalı Çok Değişkenli İstatistik Teknikleri, Asil Yayın Dağıtım, Ankara.

KELEŞ, H.N.Ç., 2006. "İş Tatmininin Örgütsel Baglıllk Üzerindeki Etkisine İlişkin İlaç Üretim ve Dagıtım Firmalarında Yapılan Bir Araştırma”, Doktora Tezi, Selçuk Üniversitesi, Konya.

KMTSO (Kahramanmaraş Ticaret ve Sanayi Odası), 04.04.2017, http:// www.kmtso.org.tr

KLINE, R. B., 2011. Principles and Practice of Structural Equation Modeling, Guilford Press, New York.

KOÇ, E., 2002. “İnsan ve Sadakat”, Felsefe Dünyası Dergisi, 1(35), ss.49-57.

KOÇ, H. ve YAZICIOĞLU, İ., 2011. "Yöneticiye Duyulan Güven ile İş Tatmini Arasındaki İlişki: Kamu ve Özel Sektör Karşılaştırması", Doğuş Üniversitesi Dergisi, 12 (1), ss. 46-57.

KOÇ, H., 2009. “Örgütsel Bağlllık ve Sadakat İlişkisi”, Elektronik Sosyal Bilimler Dergisi, 8(8), ss 200-201.

KOH, H. C. ve BOO, H.Y., 2004. "Organisational Ethics and Employee Satisfaction and Commitment", Management Decision, 42(5), ss. 677-693.

KORSGAARD, M. A., SCHWEIGER, D. M. ve SAPIENZA, H. J., 1995. "Building Commitment, Attachment and Trust in Strategic Decision- Making Teams: The Role of Procedural Justice", Academy of Management Journal, 38(1), ss. 60-84.

KRAMER, R. M. ve LEWICKI, R., 2010. “Repairing And Enhancing Trust: Approaches To Reducing Organizational Trust Deficits. The Academy Of Management Annals, 4(1), ss. 245-277.

KUMAR, A., 2016. "Emotional Intelligence Dimensions, Job Satisfaction and Primary School Teachers", IRA International Journal of Education and Multidisciplinary Studies, 5(1), ss. 8-15. 
KURU, E., 2001. “Kinestetik Zeka ve Beden Eğitimi”, G.Ü. Gazi Eğitim Fakültesi Dergisi, 21(2), ss. 217-229.

LASCHINGER, H. K., FINEGAN, J. ve SHAMIAN, J., 2001. “The Impact Of Workplace Empowerment, Organizational Trust On Staff Nurses' Work Satisfaction And Organizational Commitment", Health Care Management Review, 26(3), ss. 7-23.

LAWLER, E. E. ve PORTER, L. W., 1967. “The Effect of Performance on Job Satisfaction”, Industrial Relations: A journal of Economy and Society, 7(1), ss. 20-28.

LAZARIC, N. ve LORENZ, E., 1998. The Learning Dynamics of Trust, Reputation and Confidence. Edward Elgar Publishing, Cheltenham.

LAZARUS, R. S., 1991. Emotion and Adaption. Oxford University Press, Inc, New York.

LEITER, M. ve MASLACH, P. C, 1988. “The Impact of Interpersonal Environment on Burnout and Organizational Commitment", Journal of Organizational Behavior, 9(4), ss. 297-308.

LEONG, C. S., FURNHAM, A. ve COOPER, C. L., 1996. “The Moderating Effect of Organizational Commitment on the Occupational Stress Outcome Relationship", Human Relations, 49(10), ss. 13451361.

LEVENTHAL, H. ve SCHERER, K., 1987. “The Relationship of Emotion to Cognition: A Functional Approach to a Semantic Controversy", Cognition and Emotion, 1(1), ss. 3-28.

LEWICKI, R. ve BUNKER, B., 1995. “Trust in Relationships: A Model of Development and Decline", Conflict, Cooperation, and Justice: Essays Inspired by the Work of Morton Deutsch, Der. Bunker, B. ve Rubin J., 133-173, Jossey-Bass Inc. Publishers, San Francisco.

LEWIS, J. ve WEIGERT, A., 1985. “Trust as a Social Reality”, Social Forces, 63(4), ss. 967-985.

LOCKE, E. A. ve LATHAM, G. P., 1990. A Theory of Goal Setting \& Task Performance. Prentice-Hall, Inc., 431s.

LOCKE, E. A., 1976. “The Nature and Causes of Job Satısfaction", Handbook of Industrial and Organizational Psychology, 45, ss. 12971349. 
LOSCOCCO, K. A., 1990. "Reactions to Blue-Collar Work: A Comparison of Women and Men", Work and Occupations, 17(2), ss. 152- 177.

LUTHANS, F., 1995. Organizational Behaviour. McGraw-Hill, Inc., New York, 628s.

LYNN, A. B., 2001. The Emotional Intelligence Activity Book: 50 Activities for Promoting EQ at Work. Amacom Div American Mgmt Assn.

MACINTOSH, G. ve KRUSH, M., 2014. "Examining the Link between Salesperson Networking Behaviors, Job Satisfaction, and Organizational Commitment: Does Gender Matter?", Journal of Business Research, 67(12), ss. 2628-2635.

MARLOWE, H. A., 1986. "Social Intelligence: Evidence for Multidimensionality and Construct Independence", Journal of Educational Psychology, 78(1), ss. 52-58.

MASLOW, A. H., 1970. Motivation and Personality (887-1904). J. Fadiman, \& C. McReynolds (Eds.). New York: Harper \& Row.

MASREK, M. N., OSMAN, M. A. F., IBRAHIM, Z. ve MANSOR, A. N., 2015. "Malaysian Computer Professional: Assessment of Emotional Intelligence and Organizational Commitment", Procedia-Social and Behavioral Sciences, 172, ss. 238-245.

MATHIEU, J. E. ve ZAJAC, D. M., 1990. "A Review and Meta-Analysis of Antecedents, Correlates and Consequences of Organizational Commitment", Psychological Bulletin, 108(2), ss. 171-194.

MATTHEWS, G., ZEIDNER, M. ve ROBERTS, R. D., 2004. Emotional Intelligence: Science and Myth. MIT Press.

MAYER, J. D. ve COBB, C. D., 2000. "Educational Policy on Emotional Intelligence: Does It Make Sense?", Educational Psychology Review, 12(2), ss. 163-183.

MAYER, J. D. ve SALOVEY, P., 1993. The Intelligence of Emotional Intelligence. Intelligence, 17(4), ss. 433-442.

MAYER, J. D., 2006. A New Field Guide to Emotional Intelligence. Emotional Intelligence in Everyday Life. Psychology Press, New York, 3-26, 304s.

MAYER, J. D., CARUSO, D. R. ve SALOVEY, P., 1999. "Emotional Intelligence Meets Traditional Standards for an Intelligence", Intelligence, 27(4), ss. 267-298. 
MAYER, J.D. ve SALOVEY, P., 1997. What Is Emotional Intelligence. In P. Salovey, \& D. Sluyter, Emotional Development And Emotional Intelligence: Educational Implications (pp. 3-34). Basicbooks Inc., New York.

MAYER, R.C., DAVIS, J.H., SCHOORMAN, D., 1995. "An Integrative Model of Organizational Trust", Academy of Management Review, 20(3), ss. 709-734.

MCALLISTER, D. J., 1995. "Affect-And Cognition-Based Trust As Foundtions For Interpersonal Cooperation In Orgnisations", Academy Of Management Journal, 38(1), ss. 24-59.

MCDONALD, D. J. ve MAKIN, P. J., 2000. “The Psychological Contract, Organisational Commitment and Job Satisfaction Of Temporary Staff”, Leadership \& Organization Development Journal, 21(2), ss. 84-91.

MCGEE, G. W. ve FORD, R. C., 1987. “Two (or more?) Dimensions of Organizational Commitment: Reexamination of the Affective and Continuance Commitment Scales", Journal of Applied Psychology, 72(1), ss. 638-642.

MEYDAN, C. H. ve ŞEŞEN, H., 2005. Yapısal Eşitlik Modellemesi Amos Uygulamaları. Detay Yayıncılık, Ankara.

MEYER, J. P. ve ALLEN, N. J., 1997. Commitment in the Workplace, Theory, Research and Application, Sage Publications Inc., London, 102s.

MEYER, J. P. ve NATALIE J. A., 1996. "Affective, Continuance And Normative Commitment To The Organization: An Examination Of Construct Validity", Journal of Vocational Behavior, 49, ss. 252-276.

MEYER, J. P., STANLEY, D. J., HERSCOVITCH, L. ve TOPOLNYTSKY, L., 2002. "Affective, Continuance, and Normative Commitment to The Organization: A Meta-Analysis of Antecedents, Correlates and Consequences", Journal of Vocational Behavior, 61, ss. 20-52.

MEYER, J. P., ve ALLEN, N. J., 1990. “The Measurement and Antecedents of Affective, Continuance and Normative Commitment to the Organization", Journal of Occupational Psychology, 63(1), ss. 1-18.

1991. "A Three-Component Conceptualization of Organizational Commitment", Human Resource Review, 1(1), ss. 61-98.

1997. Commitment in The Workplace: Theory, Research, and Application. Sage Publications, US, 150s. 
MINER, J. B. 1992. Industrial and Organizational Psychology. McGraw Hill, New York.

MISHRA, A.K., 1996. "Organizational Responses To Crisis: The Centrality Of Trust”, Kramer, Roderick M. and Thomas Tyler (eds.) Trust In Organizations. Newbury Park, CA: Sage. ss. 261-287.

MISHRA, J. ve MORRISSEY, M. A., 1990. “Trust in Employee/Employer Relationships: A Survey of West Michigan Managers”, Public Personnel Management, 19 (4), ss. 443-486.

MİRZE, S. K., 2002. Introduction to Business. Literatür Yayıncilık.

MONFARED, J. H. ve AMANI, A., 2015. "Studying the Emotional Intelligence, Organizational Commitment, and Job Satisfaction”, Management and Administrative Sciences Review, 4(4), ss. 679-685.

MOORHEAD, G. ve GRIFFIN, R., 1989. Organizational Behavior. Boston.

MORGAN R. M. ve HUNT, S. D., 1994. “The Commitment Trust Theory Of Relationship Marketing”, Journal Of Marketing, 58(3), ss.20-39.

MORGAN, C. T., 1993. Psikolojiye Giriş. Ed. Sirel Karakaş, Meteksan, Ankara.

MORROW, P. C,, 1983. "Concept Redundacy in Organizational Research: The Case of Work Commitment", Academy of Management Review, 8(9), ss. 486-500.

MORROW, P. C. ve MCELROY, J. C., 1986. "Research Notes on Assessing I Measures of Work Commitment", Journal of Vocational Behaviors, 3(5), ss.53-62.

MOWDAY, R. T,, STEERS, R. M. ve PORTER, I. W, 1979. “The Measurement of Organizational Commitment", Journal of Voctional Behavior, 14(7), ss. 224-247.

MULLINS, L. J., 2007. Management and Organisational Behaviour. Pearson Education.

NAIDU, S. P., 1996. Public Administration: Concepts and Theories. Hyderabad, India: New Age International, Ltd. Publishers.

NEWSOME, S., DAY, A. L. ve CATANO, V. M., 2000. "Assessing the Predictive Validity of Emotional Intelligence", Personality and Individual Differences, 29(6), ss. 1005-1016. 
NORDIN, N., 2012. “Assessing Emotional Intelligence, Leadership Behaviour and Organizational Commitment in a Higher Learning Institution", Procedia-Social and Behavioral Sciences, 56, ss. 643-651.

NORTHCRAFT, G. B. ve NEALE, M. A., 1990. Organizational Behavior, A Management Challange, The Dryden Press, ABD, 544s.

NYHAN, R. C. ve MARLOWE, H. A., 1997. "Development And Psychometric Properties Of The Organizational Trust İnventory”, Evaluation Review, 21(5), 614-635.

O'SULLIVAN, M., GUILFORD, J. P. ve DEMILLE, R., 1965. The Measurement of Social Intelligence. Report from the Psychological Laborutory, University of Southern California, Los Angeles.

OCAKOĞLU, 2016. "Kurumun Oluşturduğu Örgütsel Güvenin, Çalışanların İşten Ayrılma Niyetine Etkisi: Gölbaşı Belediye Çalışanları Örneği” Yüksek Lisans Tezi, Türk Hava Kurumu Üniversitesi, Ankara.

ONAY, A., 2016. "Kariyer Bağlılığı, Örgütsel Bağllıı Ve İşten Ayrılma Eğilimi İlişskisi: Akademisyenler Üzerine Bir Araştırma”, Yüksek Lisans Tezi, Kocaeli Üniversitesi, Kocaeli.

OUYANG, Z., SANG, J., LI, P. ve PENG, J., 2015. “Organizational Justice and Job Insecurity as Mediators of the Effect of Emotional Intelligence on Job Satisfaction: A Study from China", Personality and Individual Differences, 76, ss. 147-152.

OXFORD İNGİLİZCE SÖZLÜĞÜ, en.oxforddictionaries.com (03.03.2017).

ÖLÇÜM, Ç.M., 2004. Örgüt Kültürü ve Örgütsel Bağlllık. Nobel Yayın, Ankara.

ÖNER, N., 1997. Türkiye'de Kullanılan Psikolojik Testler. Boğaziçi Üniversitesi Matbaası, İstanbul.

ÖRÜCÜ, E., YUMUŞAK, S. ve BOZKIR, Y., 2006. “Kalite Yönetimi Çerçevesinde Bankalarda Çalışan Personelin İş Tatmini ve İs Tatminini Etkileyen Faktörlerin İncelenmesine Yönelik Bir Araştırma”, Celal Bayar Üniversitesi İİBF Yönetim ve Ekonomi Dergisi, 13(1), ss. 39-51.

ÖTKEM, Ş., KIZILTAN, B. ve ÖZTOPRAK, M., 2016. “Örgütsel Güven İle Örgüt İkliminin Örgütsel Özdeşleşme, İş Tatmini Ve İşten Ayrılma Niyeti Üzerine Etkileri: Otel İşletmelerinde Bir Uygulama”, Journal of Business Research Turk, 8(4), ss. 162-186. 
ÖZBEK, A. ve BOZTEPE, Z., 2017. "Duygusal Zekânın İş Yaşamında Örgütsel Bağlllık ve Kariyer İlişkisi: İlkokul Öğretmenleri Sağlık ve Sosyal Yardım Sandı̆̆ı", Kırıkkale Üniversitesi Sosyal Bilimler Dergisi, 7(1), ss. 183-196.

ÖZDEVECİOĞLU M., ve AKTAŞ A., 2007. "Kariyer Bağlılığı, Mesleki Bağlılık Ve Örgütsel Bağlılığın Yasam Tatmini Üzerindeki Etkisi: İs-Aile Çatışmasının Rolü”, Erciyes Üniversitesi İktisadi ve İdari Bilimler Fakültesi Dergisi, 28, ss. 1-20.

ÖZDEVECİOĞLU, M., 2003. “Algılanan Örgütsel Destek İle Örgütsel Bağlılık Arasındaki İlişkilerin Belirlenmesine Yönelik Bir Araştırma”, Dokuz Eylül Üniversitesi İ.İ.B.F. Dergisi, 18(2), ss. 109-126.

1995, “Organizasyon Kültürü”, Stratejik Yönetim ve Liderlik, 2. Bask1, İz Yay. İstanbul .

ÖZCAN, M., GEÇİCİ, E. ve GÜNLÜK, M., 2016. "Muhasebecilerin Duygusal Zeka Düzeylerinin Örgütsel Bağlılıkları Üzerindeki Etkisi", Ege Academic Review, 16(2), ss. 287-302.

ÖZEN, J., 2003. Örgüte Duyulan Güvenin Anahtar Unsuru Olarak Örgütsel Adalet. Vadi Yayınları, Ankara.

ÖZKALP, E. ve KIREL, Ç., 2011. Örgütsel Davranış. Ekin Basın Yayın Dağıtımcılık. 5. Baskı. Bursa.

2005. Örgütsel Davranış. Anadolu Üniversitesi Yayınları.

ÖZUTKU, H., 2008. "Örgütte Duygusal, Devamlılık ve Normatif Bağlılık ile İş Performansı Arasındaki İlişkinin İncelenmesi”, İstanbul Üniversitesi İşletme Fakültesi Dergisi, 2, ss. 79-97.

PAKER, N., 2009. “İlköğretim Okulu Öğretmenlerinin Örgütsel Güvenleri ile Örgütsel Bağlılıkları Arasındaki İlişki (Sakarya İli Örneği)”. Yüksek Lisans Tezi. Sakarya Üniversitesi, Sakarya.

PAKSOY, M., 2002. Çalışma Ortamında İnsan ve Toplam Kalite Yönetimi. Santay Yayınevi, İstanbul.

PANDEY, N. ve SHARMA, M.K., 2016. “The Impact of Emotional Intelligence on Job satisfaction: Evidence from a Large Indian Bank", IUP Journal of Soft Skills, 10(3), ss. 7-23.

PAPATHANASIOU, S. ve SIATI, M., 2014. "Emotional Intelligence and Job Satisfaction in Greek Banking Sector", Research in Applied Economics, 6(1), ss. 225-239. 
PARASURAMAN, S. ve NACHMAN, S. A., 1987. "Correlates of Organizational and Professional Commitment: The Case of Musicians in Symphony Orchetras", Group and Organization Studies, 12(3), ss. 287-308.

PSU, 02.05.2017, https://wikispaces.psu.edu/display/PSYCH484/11.+Jo$\mathrm{b}+$ Satisfaction

PETTIGREW, A. P., 1979. “On Studying Organizational Cultures”, Administrative Science Quarterly, 24(4), ss. 570-581.

POLAT, S., 2009. Eğitim Örgütleri İçin Sosyal Sermaye Örgütsel Güven. Pegem Akademi Yayıncılık, Ankara, 136s.

RAHIM, M., PSENICKA, C., POLYCHRONIOU, P., ZHAO, J. H., YU, C. S., ANITA C. K., ... ve FERDAUSY, S., 2002. "A Model of Emotional Intelligence and Conflict Management Strategies: A Study in Seven Countries", The International Journal of Organizational Analysis, $10(4)$, ss. 302-326.

RANDALL, D. M. ve COTE, J. A., 1991. "Interrelationships of Work Commitment Consructs", Work and Occupations, 18(2), ss. 194211.

RATHI, N. ve RASTOGI, R., 2008. "Job Satisfaction and Psychological Well-Being", The Icfai University Journal of Organizational Behavior, 7(4), ss. 47-57.

REICHERS, A. E., 1985. "A Review and Reconceptualization of Organizational Commitment", Academy of Management Review, 10(3), ss. 465-476.

REISINGER, Y. ve TURNER, L., 1999. Structural Equation Modelling with Lisrel: Application to Tourism. Tourism Management, ss. 71 $-88$.

REIFF, H. B., HATZES, N. M., BRAMEL, M. H. ve GIBBON, T., 2001. "The Relation of LD and Gender with Emotional Intelligence in College Students", Journal of Learning Disabilities, 34(1), ss. 66-78.

REZVANI, A., CHANG, A., WIEWIORA, A., ASHKANASY, N. M., JORDAN, P. J. ve ZOLIN, R., 2016. "Manager Emotional Intelligence and Project Success: The Mediating Role of Job Satisfaction and Trust", International Journal of Project Management, 34(7), ss. 1112-1122. 
RINDFLEISCH, A., 2000. "Organizational Trust and Interfirm Cooperation: An Examination of Horizontal Versus Vertical Alliences", Marketing Letters, 11 (1): ss. 81-95.

ROBBINS, S. P. ve JUDGE, T. A., 2012. Organizational Behavior. İnci Erdem (Ed.), Örgütsel Davranış. Nobel Yayınları, Anakar, 688s.

ROEHLING, M. V., CAVANAUGH, M. A., MOYNIHAN, L. M. ve BOSWELL, W. R., 2000. “The Nature of the New Employment Relationship: A Content Analysis of the Practitioner and Academic Literatures", Human Resource Management, 39(4), ss. 305-320.

RUSBULT, C. A. ve FARREL, D, 1983. "A Longitudinal Test of the Investment Model: The Impact on Job Satisfaction, Job Commitment and Turnover of Variations in Rewards, Costs, Alternatives and Investments", Journal of Applied Psychology, 68(3), ss. 429-438.

SABAN, A., 2001. Çoklu Zeka Teorisi ve Eğitimi. Nobel Yayın Dağıtım, İstanbul, 158s.

SABUNCUOĞLU, Z. ve TÜZ, M., 2005. Örgütsel Psikoloji. Alfa Aktüel Basım Yayın, Bursa, 370s.

SAGER, J. K. ve JOHNSTON, M. W, 1989. “Antecedents and Outcomes of Organizational Commitment: A Study of Salespeople", Journal of Personal Selling and Sales Management, 9(1), ss. 30- 41.

SAKALLI, Ö. S., 2015. "Örgütsel Adalet İle Örgütsel Güven İlişkisinde Kişilik Özelliklerinin Düzenleyici Rolü Ve Bir Alan Araştırması”, Doktora Tezi, Balıkesir Üniversitesi, Balıkesir.

SALANCIK, G. R., 1977. Commitment and The Control of Organization Behavior and Belief, New Directions in Organization Behavior, Der, B. M. Sraw ve G. R. Salancik, Chicago, Illionis.St. Clair Press, ABD.

SALEH, S.D. ve HOSEK, J., 1976. "Job Involvement: Concepts And Measurements", The Academy Of Management Journal, 19(2), ss.213224.

SALOVEY, P. ve MAYER, J. D., 1990. “Emotional Intelligence”, Imagination, Cognition and Personality, 9(3), ss. 185-211.

SARP, N. ve TOSUN, A., 2011. "Duygu ve Otobiyografik Bellek, Psikiyatride Güncel Yaklaşımlar”, Current Approaches in Psychiatry, 3(3), ss. 446-465. 
SARTORIUS, M., 2008. Kadınlarda Duygusal Zeka-EQ’yu Daha İyi Kullanmanın Yolları, Çev. Şebnem Can Erendor, Redaksiyon: Özgül Eraman, 2. Baskı, Varlık Yayınları, İstanbul.

SAYIN, U., 2009. “Güven: İşletmelerde Algilanan Örgütsel Adalet ve İş Tatmini Arasındaki İlişkide Bir Aracı Uygulama”, Yüksek Lisans Tezi, Atatürk Üniversitesi, Erzurum.

SCHERMERHORN, J. R, HUNT, J. G. ve OSBORN, R. N, 1994. Managing Organziation Behavior, Fifth Edition, John Willey \& Sons, Inc., New-York, 144s.

SCHNEIDER, B. ve SNYDER, R. A., 1975. "Some Relationships between Job Satisfaction and Organization Climate", Journal of Applied Psychology, 60(3), ss. 318-328.

SCHODERBEK, P.P., COSIER, R.A. ve APLIN J.C., 1991. Management. Harcourt Brace Jovanovich Publishers, USA.

SCHUTTE, N. S., MALOUFF, J. M., HALL, L. E., HAGGERTY, D. J., COOPER, J. T., GOLDEN, C. J. ve DORNHEIM, L., 1998. "Development and Validation of a Measure of Emotional Intelligence", Personality and Individual Differences, 25(2), ss. 167-177.

SEVIMLİ, F. ve IŞCAN, Ö. F., 2005. "Bireysel ve İş Ortamina Ait Etkenler Açısından İş Doyumu”, Ege Academic Review, 5(1), ss. 55-64.

SHAFER, W. E, PARK, L. J. ve LIAO, W. M, 2002. “Professionalism, Organizational-Professional Conflict and Work Outcomes: A Study of Certified Management Accountants", Accounting Auditing \& Accountability Journal, 15(1), ss 46-48.

SHAFIQ, M. ve RANA, R. A., 2016. "Relationship of Emotional Intelligence to Organizational Commitment of College Teachers in $\mathrm{Pa}$ kistan", Eurasian Journal of Educational Research, 16(62), ss. 1-14.

SHAPIRO, D., SHEPPARD, B. ve CHERASKIN, L., 1992. "Business on a Handshake”, Negotiation Journal, 8(4), ss. 365-377.

SHELDON, M. E., 1971. "Investments and Involvements as Mechanisims Producing Commitment to the Organization", Administrative Science Quarterly, 16(1), ss.143-150.

SHOOSHTARIAN, Z., AMELI, F. ve AMINILARI, M., 2013. “The Effect of Labor's Emotional Intelligence on Their Job Satisfaction, Job Performance and Commitment", Iranian Journal of Management Studies, 6(1), ss. 29-45. 
SOLMUŞ, T., 2004. İş Yaşamında Duygular ve Kişilerarası İlişkiler. Beta Basım Yayım Dağıtım, İstanbul, 238s.

SOMERS, M., ve BIRNBAUM, D., 2000. "Exploring The Relationship Between Commitment Profiles And Work Attitudes, Employee Withdrawal, And Job Performance", 29(3), ss. 353-366.

SÖKMEN, A., 2000. "Ankaradaki Beş Yıldızlı Konaklama İşletmelerinde Örgütsel Bağlılık ile İşgören Performansı Arasındaki İlişkinin Belirlenmesine Yönelik Ampirik Bir Araştırma”, Yüksek Lisans Tezi, Gazi Üniversitesi, Ankara.

SPECTOR, P. E., 1997. Job Satisfaction: Application, Assessment, Causes, and Consequences. Sage Publications.

STATT, D. A., 2004. The Routledge Dictionary of Business Management. Routledge.

STEPHENS, E. C. ve DUNN, J. D., 1972. Management of Personal Manpower Management and Organizational Behavior. Mc Graw Hill Book, New York.

STERNBERG, R. J., 1990. Metaphors of Mind: Conceptions of the Nature of Intelligence. Cambridge University Press, Cambridge, 364s.

STEVEN, J.S. ve BOOK, H.E., 2003. EQ-Duygusal Zeka ve Başarının Sırrı, (1.Basım), Özgür Yayınları, İstanbul, 320s.

STRAITER, K. L., 2005. “The Effects Of Supervisors Trust Of Subordinates And Their Organization On Job Satisfaction And Organizational Commitment", International Journal Of Leadership Studies, $1(1)$, ss. 86-101.

SULIMAN, A. M. T., 2002. "Is it Really a Mediating Construct? The Mediating Role of Organizational Commitment in Work Climate-Performance relationship", Journal of Management Development, 21(3), ss. 170-183.

SUN, H. Ö., 2002. İş Doyumu Üzerine Bir Araştırma: Türkiye Cumhuriyeti Merkez Bankası Banknot Matbaası Genel Müdürlügü. Ankara.

SWARNALATHA, C. ve SURESHKRISHNA, G., 2013. "Emotional Intelligence and Job Satisfaction: A Study among Employees of Automotive Industries in India”, International Business Management, 7(1), ss. 46-49. 
ŞENATALAR, F., 1978. Personel Yönetimi ve Beşeri İlişkiler. İ. Ü. Kitabevi, İstanbul, 507s.

ŞİMŞEK, M. Ş., AKGEMCİ, T. ve ÇELİK, A., 2014. Davranış Bilimlerine Giriş ve Örgütlerde Davranış. Nobel Yayınları, Ankara, 412s.

ŞİMŞEK, Ş., 1998. Yönetim ve Organizasyon. İstanbul Üniversitesi Yayınları, İstanbul.

ŞİMŞEK, L., 1995. “İş Tatmini”, Verimlilik Dergisi, 12.

TAN, H. H. ve LIM, A. K. H., 2009. "Trust in Coworkers and Trust in Organizations", The Journal of Psychology, 143(1), ss. 45-66.

TAN, H. H. ve TAN, C. S., 2000. “Toward the Differentiation of Trust in Supervisor and Trust in Organization”, Genetic, Social and General Psychology Monographs, 126(2), s. 241-260.

TANNER, B. M., 2007. "An Analysis of the Relationships among Job Satisfaction, Organizational Trust, and Organizational Commitment in an Acute Care Hospital", Doctoral Dissertation, Saybrook University.

TARHAN, N., GÜMÜŞEL, O. ve SAYIM A., 2014. Pozitif Psikoloji Çoklu Zeka Uygulamaları. 4. Baskı. Timaş Yayınları. İstanbul.

TDK (Türk Dil Kurumu), www.tdk.gov.tr (03.03.2017).

TELLA, A., AYENI, C. O. ve POPOOLA, S. O., 2007. "Work Motivation, Job Satisfaction, and Organisational Commitment of Library Personnel in Academic and Research Libraries in Oyo State, Nigeria", Library Philosophy and Practice (e-journal), ss. 1-12.

TELMAN, N. ve ÜNSAL, P., 2004. Çalışan Memnuniyeti. Epsilon.

TEREKLİ, G., 2010. “Örgütsel Güven Boyutları ve İş Tatmini İlişkisi: Tekstil İşletmesinde Bir Araştırma”, Yüksek Lisans Tezi, Eskişehir Anadolu Üniversitesi, Eskişehir.

TETIKK, S., ÖKMEN, M. ve BAL, V., 2014." Meslek Yüksekokulu Öğrencilerinin Duygusal Zeka Düzeyleri ile Öfke Düzeyleri ve Öfke İfade Tarzları Arasındaki İlişkinin İncelenmesi”, Elektronik Mesleki Gelişim ve Araştırma Dergisi, 2(1), ss. 17-29.

THARIKH, S. M., YING, C. Y. ve SAAD, Z. M., 2016. "Managing Job Attitudes: The Roles of Job Satisfaction and Organizational Commitment on Organizational Citizenship Behaviors", Procedia Economics and Finance, 35, ss. 604-611. 
THORNTON, R., 1970. "Organizational Involvement and Commitment to Organization and Profession, Administartive Science Quarterly", 15(2), ss. 417-426.

TİKİCİ, M. ve DERİN, N., 2013. Örgütsel Güven. Edip Örücü ve Engin Üngüren (Ed.), Örgütsel Davranış (P. 609-626), Lisans Yayıncılık, İstanbul.

TİMUROĞLU, M. K. ve GÜRKAN, H., 2016. "Çalışanlarda Tutumsal Bağlılık ile Duygusal Zekânın Özbilinç Alt Boyutu Arasındaki İlişkinin İncelenmesi”, Bitlis Eren Üniversitesi Sosyal Bilimler Enstitüsü Dergisi, 5, ss. 113-144.

TOKER, F., 1968. Zeka Kuramları. Milli Eğitim Bakanlığı Talim ve Terbiye Dairesi Araştırma ve Değerlendirme, Ankara.

TOKSÖZ, S,. 2015. “Çalışanların Öğrenen Örgüt Algılarının İş Tatmini, Örgütsel Bağlllık ve Örgüt İçi Girişimcilikleri Üzerindeki Etkisi: Bilişim Sektörü Üzerine Bir Çalışma”, Doktora Tezi, Okan Üniversitesi.

TOLAY, E., 2003. “Eğitimin Örgütsel Bağlılığa Etkileri”, Yüksek Lisans Tezi, Dokuz Eylül Üniversitesi, İzmir.

TOP, M., 2012. "Hekim ve Hemşirelerde Örgütsel Bağl1lık, Örgütsel Güven ve İş Doyumu Profili”, İstanbul Üniversitesi İşletme Fakültesi Dergisi, 41(2), ss. 258-277.

TOPALOĞLU, I. G,. 2010. “İşgörenlerin Adalet ve Etik Algıları Açısından Örgütsel Güven ile Örgütsel Bağlılık İlişkisi”, Yüksek Lisans Tezi, Atılım Üniversitesi, Ankara.

TOPRAK, O., 2006. “Örgütsel Güvenin Performans Üzerindeki Etkisi ve Bankacılık Sektöründe Bir Uygulama”, Yüksek Lisans Tezi, Gaziantep Üniversitesi, Gaziantep.

TRIVELLAS, P., GEROGIANNIS, V. ve SVARNA, S., 2013. “Exploring Workplace Implications of Emotional Intelligence (WLEIS) in Hospitals: Job Satisfaction and Turnover Intentions", Procedia-Social and Behavioral Sciences, 73, ss. 701-709.

TSAI, M. C., CHENG, C. C. ve CHANG, Y. Y., 2010. "Drivers of Hospitality İndustry Employees' Job Satisfaction, Organizational Commitment and Job Performance", African Journal of Business Management, 4(18), ss. 4118-4134. 
TSAI, M. Y., 2016. "Research on Multiple Intelligences of Junior High School Students with Different Background Variables", Journal of Modern Education Review, 6(1), ss. 10-18.

TSCHANNEN, M. ve HOY, W. K., 2000. "A Multidisciplinary Analysis of the Nature, Meaning and Measurement of Trust" Review of Educational Research, 70 (4), ss. 547-593.

TSUI, A. S., EGAN, T. D. ve O'REILLY, C. A., 1992. “Being Different: Relational Demography and Organizational Attachment”, Administrative Science Quarterly, 37(1), ss. 549-580,.

TUĞRUL, C., 1999. “Duygusal zeka”, Klinik Psikiyatri, 1, ss. 12-20.

TUTAR, H., 2007. "Erzurum'da Devlet ve Özel Hastanelerde Çalışan Sağlık Personelinin İşlem Adaleti, İş Tatmini ve Duygusal Bağlılık Durumlarının İncelenmesi”, Süleyman Demirel Üniversitesi İktisadi ve İdari Bilimler Fakültesi, 12 (3), ss. 97-120.

TÜZÜN, K. İ., 2006. “Örgütsel Güven, Örgütsel Kimlik ve Örgütsel Özdeşleşme İlişkisi; Uygulamalı Bir Çalışma”, Doktora Tezi, Gazi Üniversitesi, Ankara.

UNUTMAZ, S., 2014. "Factors Affecting Job Satisfaction of Employees in a Public Instiiution”, Yüksek Lisans Tezi, Middle East Technical University, Ankara.

USLU, O. ve ARDIÇ, K., 2013. “Güç Mesafesi Örgütsel Güveni Etkiler Mi?”, Afyon Kocatepe Üniversitesi İ̉BF Dergisi, 2, ss.313-338.

UYGUÇ, N. ve ÇIMRIN, D., 2004. "DEÜ Araştırma ve Uygulama Hastanesi Merkez Laboratuvarı Çalışanlarının Örgüte Bağlılıklarını ve İșten Ayrılma Niyetlerini Etkileyen Faktörler”, D.E.Ü.İ.İ.B.F. Dergisi, 19(1), ss. 91-99

UZUNÖZ, A. ve AKBAŞ, Y., 2011. “Coğrafya Dersinde Çoklu Zekâ Destekli Öğretimin Öğrenci Başarisi ve Kaliciliğa Etkisi”, Türk Eğitim Bilimleri Dergisi, 9(3), ss. 467-496.

ÜÇÜNCÜ, K., 2016. İş Tatmini ve Motivasyon. KTÜ Orman Endüstri Mühendisliği Bölümü, (http://docplayer.biz.tr/18176069-Is-tatmini-ve-motivasyon.html).

ÜNAL, A., 2006. “İlköğretim Öğrencilerinin Gelecek İle İlgili Umutlar1nın Yapısal Eşitlik Modelleriyle Belirlenmesi”, Yüksek Lisans Tezi, Osmangazi Üniversitesi, Eskişehir. 
VALENTINE, S, GODKIN, L. ve LUCERO, M., 2002. "Ethical Context, Organizational Commitment and Person-Organization Fit", Journal of Business Ethics, 41(1), ss. 349-360.

VAN SELL, M., BRIEF, A. ve SCHULER, R, 1981. "Role Conflict and Role Ambiquity: Integration of the Literature and Directions for Future Research", Human Relations, 34(1), ss. 43-71.

VANDENBERGHE, C. ve MICHEL T., 2008. “The Role of Pay Satisfaction and Organizational Commitment in Turnover Intentions: A Two Sample Study", J Bus Psychol, 22, ss. 275-286.

VAROĞLU, D., 1993. "Kamu Sektörü Çalışanlarının İşlerine ve Kuruluşlarına Karşı Tutumları, Bağlılıkları ve Değerleri”, Doktora Tezi, Ankara Üniversitesi, Ankara.

VROOM, V. H., 1967. Work And Motivation. John Wiley and Sons Inc, New York.

V.U., 01.05.2017, https://www.villanovau.com/resources/hr/importance-of-job-satisfaction-in-the-workplace/\#.WJb2WNKLRH0

WAHN, J. C., 1998. "Sex Differences In The Continuance Component or Organization Commitment”, Group \& Organizational Management, 23(3), ss. 256-268.

WALLACE, J. E., 1995. "Corporatist Control and Organizational Commitment among Professionals: The Cas of Lawyers Working in Law Firm", Social Forces, 7(3), ss. 811-839.

WALTON, R. E., 1985. “From Control To Commitment İn The Workplace”, Harvard Business Review, 85(2), ss. 77-85.

WARDAYATI, S. M., 2016. “The Implementation of COSO Concept in "Vroom" Expentancy Theory on PT. UMC Zusuki Jember", Procedia-Social and Behavioral Sciences, 219, ss. 784-791.

WEINER, Y., ve GECHMAN, A. S, 1977. “Commitment: A Behavioral Appraoach to Job Involvement", Journal of Vocational Behavior, 10(1), ss. 44-53.

WEISINGER, H., 1998. Emotional Intelligence at Work. Jossey-Bass, San Francisco.

WHİTENER, E. M., BRODT, S. E, KORSGARD, M. A. ve WERNER, J. M., 1998. "Managers as Initiators of Trust: An Exchange Rela- 
tionship Framework for Understanding Managerial Trustworthy Behavior", The Academy of Management Review, 23(3), ss. 513-530. WONG, C. ve LAW, K.S., 2002. "The Effects of Leader and Follower Emotion Intelligence on Performance and Attitude: An Exploratory Study", The Leadership Quarterly, 13(3), ss. 243-274.

WIENER, Y., 1982. "Commitment in Organizations: A Normative View", Academy of Management Review, 7(3), ss. 418-428.

WITT, L. A., 1993. "Reactions to Work Assignment as Predictors of Organizational Commitment: The Moderating Effect of Occupational Identification, Journal of Business Research", 26(l), ss. 17-30.

YALÇIN, A., ve İPLİK, F. N., 2005. "Beş Yıldızlı Otellerde Çalışanların Demografik Özellikleri İle Örgütsel Bağlılıkları Arasındaki İlişkiyi Belirlemeye Yönelik Bir Araştırma: Adana İli Örneği”, Çukurova Üniversitesi Sosyal Bilimler Enstitüsü Dergisi, 14 (1), ss. 395-412.

YAŞIN, T., 2016. "Kişilik Özellikleri ve Psikolojik Sermayenin Psikolojik İyi Oluş, Akış Deneyimi, İş Tatmini ve Çalışan Performansına Etkileri”, Doktora Tezi, Başkent Üniversitesi, Ankara.

YANG, F. H. ve CHANG, C. C., 2008. "Emotional Labour, Job Satisfaction and Organizational Commitment Amongst Clinical Nurses: A Questionnaire Survey", International Journal of Nursing Studies, 45(6), ss. 879-887.

YAZICIOĞLU, İ., 2009. “Konaklama İşletmelerinde İşgörenlerin Örgütsel Güven Duyguları ile İş Tatmini ve İşten Ayrılma Niyetleri Üzerine Bir Alan Araştırması", Electronic Journal of Social Sciences, 8(30), ss. 235-249.

YELKİKALAN, N., 2006. “21. Yüzyılda Girişimcinin Yeni Özelliği: Duygusal Zeka”, Girişimcilik ve Kalkınma Derğisi, 1(2), ss. 39-51.

YENİCE, N. ve AKTAMIŞ, H., 2010. "Sınıf Öğretmeni Adaylarının Çoklu Zekâ Alanlarının Demografik Özelliklere Göre İncelenmesi”, Türk Fen Eğitimi Dergisi, 7(3), ss. 86-99.

YEŞİL, S., 2013. Küreselleşme ve Değiş̧en Çevre Dinamikleri Işı̆̆ında Yeni Yönetim Yaklaşımlarından Seçme Konular, Seçkin Yayıncılık, Ankara, 442s.

YEŞİLYURT, H. ve KOÇAK, N., 2014. “İş Doyumu ve Örgütsel Vatandaşlık Davranışı Arasındaki İlişkinin Otel İşletmeleri Açısından 
İncelenmesi”, Dokuz Eylül Üniversitesi Sosyal Bilimler Enstitüsü Dergisi, 16(2), ss. 303-324.

YOUSEF, D. A., 2002. "Job Satisfaction as a Mediator of the Relationship Between Job Stressors and Affective, Continuance and Normative Commitment: A Path Analytical Approach", International Journal of Stress Management, 9(2), ss. 101- 102.

YUKL, G. A. ve WEXLEY, K. N., 1971. Readings in Organizational and Industrial Psychology, Oxford University Press.

YÜCEL, I. ve BEKTAŞ, C., 2012. "Job Satisfaction, Organizational Commitment and Demographic Characteristics Among Teachers in Turkey: Younger is Better?", Procedia-Social and Behavioral Sciences, 46 , ss. 1598-1608.

YÜKSEL, F., 2009. “Ortaöğretim Kurumlarında Örgüt Kültürü İle Örgütsel Güven Arasındaki İlişki”, Yüksek Lisans Tezi, Maltepe Üniversitesi, İstanbul.

ZAHRA, S. A., 1984. "Understanding Organizational Commitment, Supervisory Management”, 29(3), ss. 16-20.

ZEFAANE, R., 1994. "Patterns of Organizational Commitment and Perceived Management Style: A Comparison of Public and Private Sector Employees”, Human Relations, 47(8), ss. 977-1007.

ZEHİR, C., MÜCELDİLİ, B. ve ZEHİR, S. 2012. “The Moderating Effect of Ethical Climate on the Relationship between Job Satisfaction and Organizational Commitment: Evidence from Large Companies in Turkey", Procedia-Social and Behavioral Sciences, 58, ss. 734-743.

ZEIDNER, M., MATTHEWS, G. ve ROBERTS, R. D., 2004. "Emotional Intelligence in the Workplace: A Critical Review", Applied Psychology, 53(3), ss. 371-399.

ZORLU, Y. P., 2006. “Örgütsel Güven ve İş Tatmini İlişkisi ve Bir Araştırma”, Yüksek Lisans Tezi, İstanbul Üniversitesi, İstanbul. 